\title{
Oak Ridge National Laboratory Commissioning Plan for the Cameca ${ }^{\circledR}$ NanoSIMS 50L
}

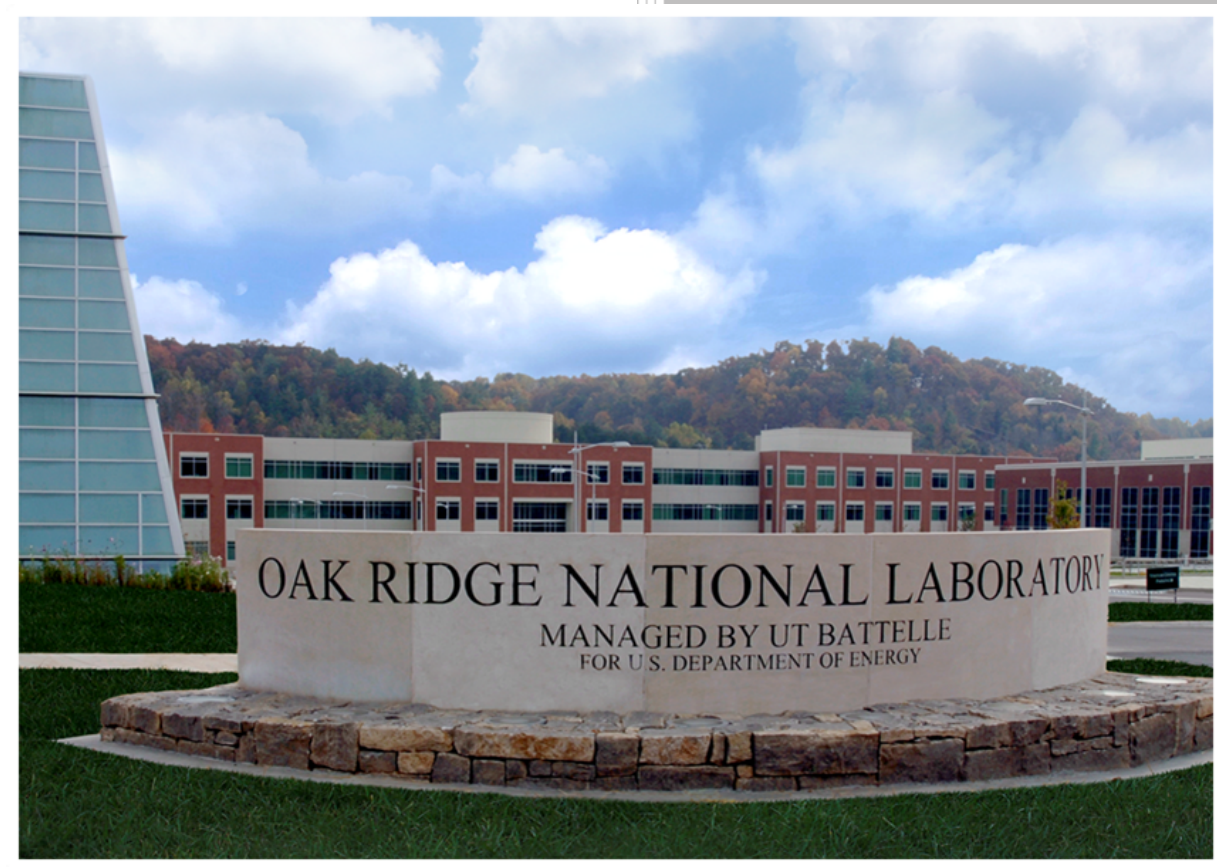

Approved for public release. Distribution is unlimited.

N. Alex Zirakparvar Julie B. Smith

August 2018 


\title{
DOCUMENT AVAILABILITY
}

Reports produced after January 1, 1996, are generally available free via US Department of Energy (DOE) SciTech Connect.

Website www.osti.gov

Reports produced before January 1, 1996, may be purchased by members of the public from the following source:

\author{
National Technical Information Service \\ 5285 Port Royal Road \\ Springfield, VA 22161 \\ Telephone 703-605-6000 (1-800-553-6847) \\ TDD 703-487-4639 \\ Fax 703-605-6900 \\ E-mail info@ntis.gov \\ Website http://classic.ntis.gov/
}

Reports are available to DOE employees, DOE contractors, Energy Technology Data Exchange representatives, and International Nuclear Information System representatives from the following source:

Office of Scientific and Technical Information

PO Box 62

Oak Ridge, TN 37831

Telephone 865-576-8401

Fax 865-576-5728

E-mail reports@osti.gov

Website http://www.osti.gov/contact.html

This report was prepared as an account of work sponsored by an agency of the United States Government. Neither the United States Government nor any agency thereof, nor any of their employees, makes any warranty, express or implied, or assumes any legal liability or responsibility for the accuracy, completeness, or usefulness of any information, apparatus, product, or process disclosed, or represents that its use would not infringe privately owned rights. Reference herein to any specific commercial product, process, or service by trade name, trademark, manufacturer, or otherwise, does not necessarily constitute or imply its endorsement, recommendation, or favoring by the United States Government or any agency thereof. The views and opinions of authors expressed herein do not necessarily state or reflect those of the United States Government or any agency thereof. 
Nuclear Security and Isotope Technology Division

\section{COMMISSIONING PLAN FOR THE CAMECA® NANOSIMS 50L}

N. Alex Zirakparvar

Julie B. Smith

Date Published: August 102018

Prepared by

OAK RIDGE NATIONAL LABORATORY

Oak Ridge, TN 37831-6283

managed by

UT-BATTELLE, LLC

for the

US DEPARTMENT OF ENERGY

under contract DE-AC05-00OR22725 



\section{CONTENTS}



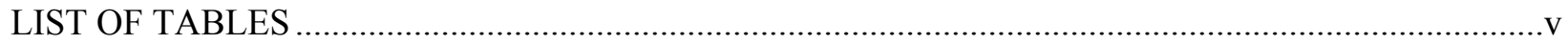

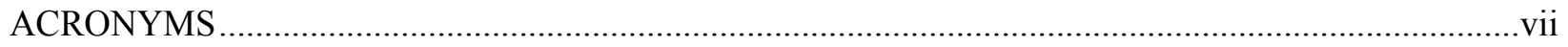

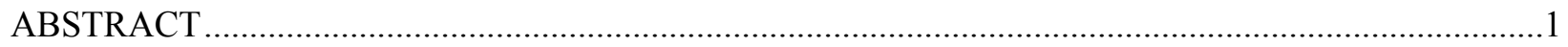

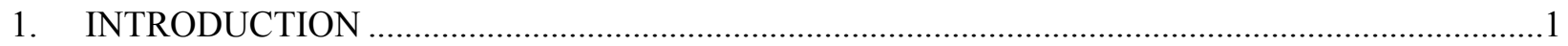

2. LITERATURE REVIEW AND CONCEPTUAL FRAMEWORK FOR NANOSIMS

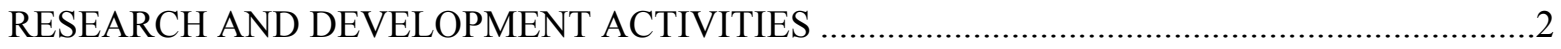

2.1 LITERATURE REVIEW: SIMS FOR NUCLEAR FORENSIC APPLICATIONS...................

2.1.1 Early days of SIMS nuclear particle analysis and evolution of instrumental methods.....

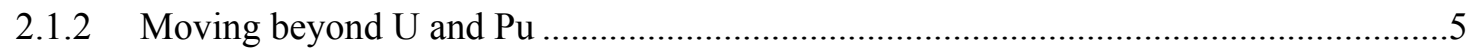

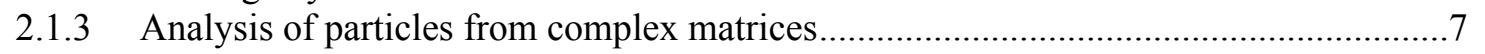

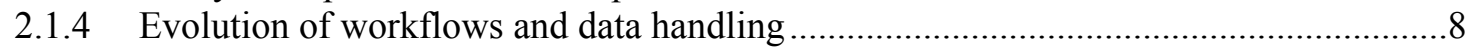

2.1.5 Understanding the effects of analytical substrate .....................................................

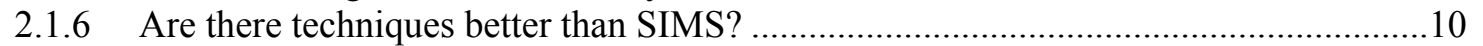

2.2 HOW DOES THE NANOSIMS 50L FIT INTO THIS LANDSCAPE? ................................11

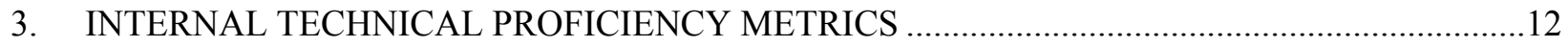

3.1 DEMONSTRATION OF CAMECA® NANOSIMS FACTORY/INSTALLATION

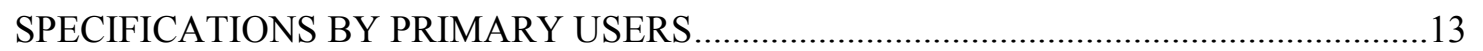

3.1.1 Tune instrument to achieve greatest transmission at highest MRP ............................13

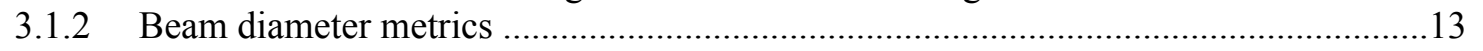

3.1.3 Reproducibility of silicon isotope ratios $\left({ }^{29} \mathrm{Si} /{ }^{28} \mathrm{Si}\right.$ and $\left.{ }^{30} \mathrm{Si} /{ }^{28} \mathrm{Si}\right)$ measurements on electron multipliers ................................................................................13

3.1.4 Reproducibility of silicon isotope ratios $\left({ }^{29} \mathrm{Si} /{ }^{28} \mathrm{Si}\right.$ and $\left.{ }^{30} \mathrm{Si} /{ }^{28} \mathrm{Si}\right)$ measurements

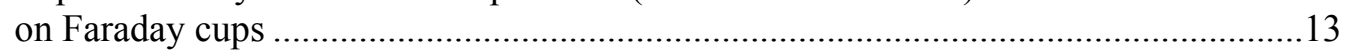

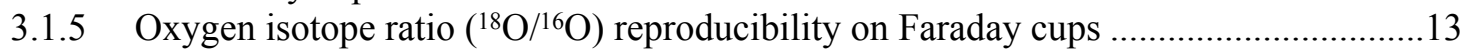

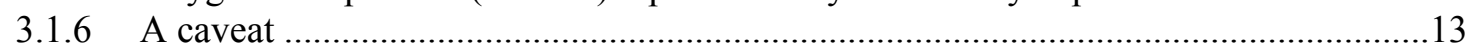

4. IMPLEMENTATION OF ANALYTICAL METHODS RELEVANT TO SPONSOR NEEDS ........14

4.1 PREPARATION AND ANALYSIS OF U-SERIES STANDARDS …..................................14

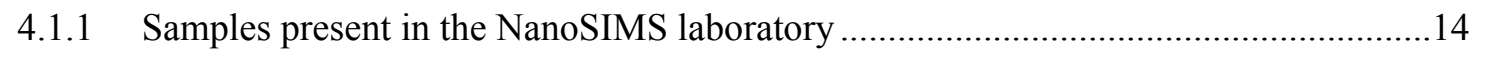

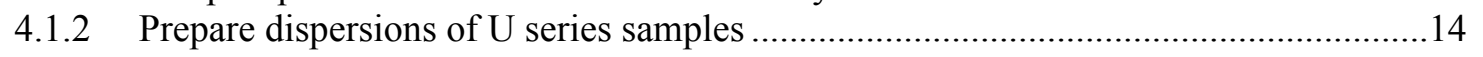

4.2 RADIOGENIC ISOTOPE RATIO MEASUREMENTS RELEVANT TO NUCLEAR

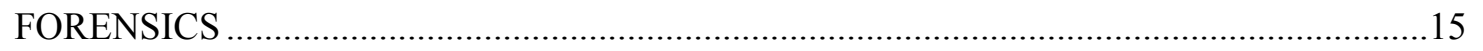

4.3 UNDERSTANDING FACTORS THAT AFFECT RESULTS................................................15

4.3.1 Spatial resolution versus analytical precision and accuracy in particle analysis ..........15

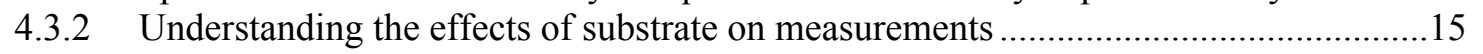

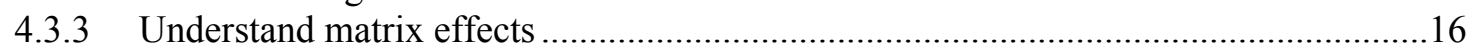

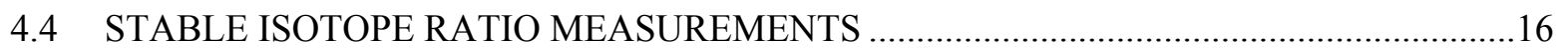

5. DEMONSTRATION OF PROFICIENCY TO THE SCIENTIFIC COMMUNITY AND

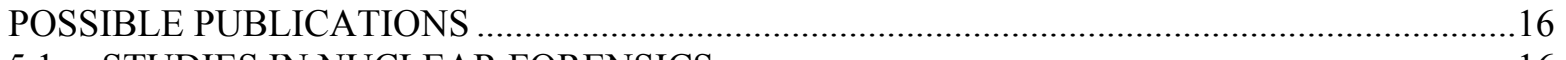

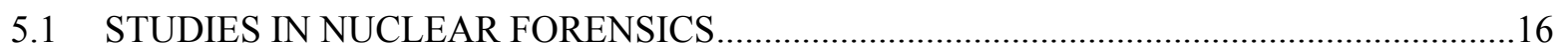

5.1.1 R\&D possibilities related to determining the fluorine content of $\mathrm{UO}_{2} \mathrm{~F}_{2} \ldots \ldots \ldots \ldots \ldots \ldots . \ldots \ldots$

5.1.2 R\&D possibilities related to matrix effects of $\mathrm{U}^{+}$secondary ion production ...............18

5.1.3 R\&D possibilities related to the detection and measurement of non-U species within materials of interest to nuclear forensics applications .....................................19

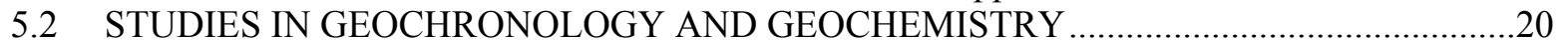

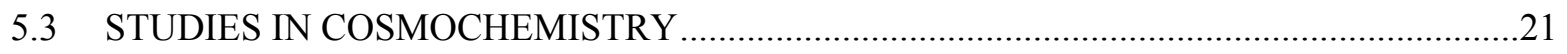

5.4 STUDIES IN ENERGY RESOURCE SCIENCE ...........................................................21 
5.5 STUDIES IN BIOLOGY

6. COMMISSIONING TIMELINE AND CONCLUDING REMARKS.

7. REFERENCES

APPENDIX A. SUMMARY OF ACTINIDE PARTICLE ANALYSIS BY SIMS A-1 


\section{LIST OF FIGURES}

Figure 1. Timeline for the ORNL NanoSIMS 50L installation and commissioning...............................2

Figure 2. Schematic illustrating the approach to developing a method for the NanoSIMS analysis

of REE $+\mathrm{Y}$ and environmental toxins in CFA.

\section{LIST OF TABLES}

Table 1. Number of publications containing NanoSIMS data according to various scientific disciplines (Adapted from Horreard 2017). 3

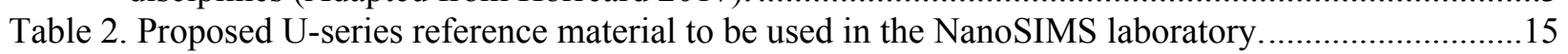

Table 3. List of SRMs possibly needed to demonstrate capability to the academic community.................22 



\section{ACRONYMS}

CFA coal fly ash

EDS energy dispersive spectroscopy

FAT factory acceptance test

IAEA International Atomic Energy Agency

ICP-MS inductively coupled plasma-mass spectrometry

LA-ICP-MS laser ablation-inductively coupled plasma-mass spectrometry

LDRD Laboratory Directed Research and Development

MIBI Multiplexed Ion Beam Imaging

MRP mass resolving power $(\Delta \mathrm{M} / \mathrm{M})$

MC Multicollection (refers to secondary ion detectors on the SIMS instrument)

NIST National Institute of Standards and Technology

NSAT Nuclear Security Advanced Technologies

ORNL Oak Ridge National Laboratory

$\mathrm{R} \& \mathrm{D} \quad$ research and development

$\mathrm{REE}+\mathrm{Y} \quad$ rare earth elements and yttrium

ROI region of interest

RSF relative sensitivity factor

RSS Research Safety Summary

SEM scanning electron microscopy

SIMS secondary ion mass spectrometry

SRM standard reference material

TEM transmission electron microscopy

TIMS thermal ionization mass spectrometry

TOF-SIMS time of flight-secondary ion mass spectrometry

XRD X-ray diffraction 



\begin{abstract}
In late March 2017 a Cameca ${ }^{\circledR}$ NanoSIMS 50L was delivered to the Nuclear Security Advanced Technologies (NSAT) group at Oak Ridge National Laboratory (ORNL). This instrument occupies the cutting edge of secondary ion mass spectrometry (SIMS) technology and provides the group with unique capabilities to serve the needs of the nuclear security research and development community. This document describes the processes whereby the ORNL NanoSIMS 50L will be commissioned, culminating in the group's ability to demonstrate both depth of proficiency and breadth of capability to sponsors and the broader community. Before describing the specific metrics and benchmarks defining the commissioning process, this document delves into the body of literature specific to SIMS analysis in support of nuclear forensics research. This in-depth literature review sets the stage for an explanation of how the NanoSIMS 50L platform will help address existing research questions and define new ones. Lastly, the document describes the measurements and projects that will take place as part of the instrument's commissioning phase.
\end{abstract}

\title{
1. INTRODUCTION
}

Secondary ion mass spectrometry (SIMS) is an elemental and isotopic analysis technique utilizing a primary ion beam (typically $\mathrm{Cs}^{+}$or $\mathrm{O}^{-}$) to trigger a collision cascade within the target material that results in the production of secondary ions. These ions, which can be individual atoms or molecular species, are then transmitted through a mass spectrometer and ultimately counted on Faraday cups, electron multipliers, or both (Ireland 1995). The fundamental basis for modern SIMS analysis was developed over 50 years ago (see discussion by Hoppe et al. 2013), but it was not until the development of the Sensitive High Resolution Ion Microprobe (SHRIMP) and IMS-3f instruments by Australia National University in 1977 (Clement et al. 1977) and Cameca ${ }^{\circledR}$ in 1980 (Lepareur 1980), respectively, that SIMS gained traction as an analytical tool across a wide range of disciplines. Although fully summarizing the evolution of this technique from its inception to the present condition is well beyond the scope of this commissioning plan document, thorough synopses of the topic can be found in Benninghoven et al. (1987), Ireland (1995), Shimizu and Hart (1982), and Hoppe et al. (2013). However, it is important to emphasize that progressive methodological developments have primarily been focused on obtaining better mass resolution, increased sensitivity, and smaller primary beam diameters.

The NanoSIMS 50L, manufactured by Cameca ${ }^{\circledR}$, is the culmination of decades of progressive methodological improvement and is well recognized as possessing the highest spatial resolution and sensitivity compared to existing production-model SIMS instruments. It should be noted (e.g., Hoppe et al. 2013) that the term "NanoSIMS" refers to both a specific class of instruments and a technique, which is appropriate in this case because an entirely new category of analyses have been made possible by the high spatial resolution measurements that are only possible with the NanoSIMS. The NanoSIMS received by ORNL (production number 42) is the 50L model (Cameca ${ }^{\circledR} 2016$ ), which has improvements to the secondary ion detector setup and flexibility, as well as changes to the instrument-user interface, relative to earlier NanoSIMS models. Another key improvement over early NanoSIMS models is the replacement of the oxygen duoplasmatron source with a new radio-frequency plasma oxygen ion source capable of achieving spatial resolution down to $50 \mathrm{~nm}$ compared with $200 \mathrm{~nm}$ using the duoplasmatron. This places ORNL in a strong position to apply this cutting-edge technique to more complex and challenging scientific questions of national and global significance. The primary purpose of this document is to provide an outline of the commissioning process for the ORNL NanoSIMS 50L.

The primary goal of the instrument commissioning process (Figure 1) is to develop an analytical facility that is capable of meeting sponsor needs. Part of achieving this goal rests in demonstrating to the broader scientific community that the facility is equipped with an operational instrument and staffed by capable 
SIMS scientists. The other part of achieving this goal rests in developing internal knowledge of the instrument's capabilities and limitations for the specific types of scientific questions that are relevant to sponsor interests. Therefore, the NanoSIMS 50L's commissioning phase extends well beyond successful installation and operator training. Following a literature review explaining how the SIMS technique has been applied to nuclear forensic science research, this document explains the metrics that will be used to (1) demonstrate internally (including to sponsors) the facility's technical proficiency in performing a wide variety of isotopic and elemental analyses at the highest possible spatial resolution (especially those analyses that are relevant to sponsor needs) and (2) demonstrate to the broader scientific community (through publications) that data generated at the ORNL NanoSIMS 50L facility are of the highest possible quality.

\begin{tabular}{|c|c|c|c|c|c|c|c|c|c|c|c|c|c|c|c|c|c|c|c|c|}
\hline \multirow[b]{2}{*}{ Activity } & \multicolumn{11}{|c|}{ GFY2017 } & \multicolumn{9}{|c|}{ GFY2018 } \\
\hline & Nov & Dec & Jan & Feb & Mar & Apr & May & Jun & Jul & Aug & Sep & oct & Nov & Dec & Jan & $\mathrm{Feb}$ & Mar & Apr & May & Jun \\
\hline \multicolumn{21}{|l|}{ FAT } \\
\hline \multirow{2}{*}{\multicolumn{21}{|c|}{ Delivery }} \\
\hline & & & & & & & & & & & & & & & & & & & & \\
\hline \multicolumn{21}{|l|}{ Installation } \\
\hline \multirow{2}{*}{\multicolumn{21}{|c|}{ Basic specifiations }} \\
\hline & & & & & & & & & & & & & & & & & & & & \\
\hline \multicolumn{21}{|l|}{ Basic training } \\
\hline \multirow{2}{*}{\multicolumn{21}{|c|}{ Isotopic specifications }} \\
\hline & & & & & & & & & & & & & & & & & & & & \\
\hline \multicolumn{21}{|c|}{ Internal technical metrics } \\
\hline \multirow{2}{*}{\multicolumn{21}{|c|}{ Advanced training }} \\
\hline & & & & & & & & & & & & & & & & & & & & \\
\hline \multirow{2}{*}{\multicolumn{21}{|c|}{ Sponsor R\&D }} \\
\hline \multirow{2}{*}{\multicolumn{21}{|c|}{ Academic R\&D }} \\
\hline & & & & & & & & & & & & & & & & & & & & \\
\hline Funding solicitation & & & & & & & & & & & & & & & & & & & & \\
\hline & & & & & & & & & & & & & & & & & & & & \\
\hline
\end{tabular}

Figure 1. Timeline for the ORNL NanoSIMS 50L installation and commissioning. Gray bars represent the originally planned timing of the activity, whereas the red bars represent the updated timeline based on when the activity occurred; the blue bars represent the new projected timing. The timeline has continually been adjusted because of unanticipated technical difficulties before delivery as well as during installation and commissioning.

\section{LITERATURE REVIEW AND CONCEPTUAL FRAMEWORK FOR NANOSIMS RESEARCH AND DEVELOPMENT ACTIVITIES}

At the time of preparing this document, there were approximately 541 published journal articles reporting data collected with a NanoSIMS instrument. These publications are spread across a wide range of scientific disciplines (Table 1) and typically also contain data collected using other techniques. In some cases, the NanoSIMS data are at the core of the study, whereas in other studies the NanoSIMS data are ancillary. It would be impossible to meaningfully summarize the full body of NanoSIMS literature within the scope of this commissioning plan, so the interested reader is referred to the Cameca ${ }^{\circledR}$ website ${ }^{1}$ where an up-to-date list of publications containing NanoSIMS data can be accessed. Nonetheless, it is important to emphasize that the NanoSIMS platform has provided a means for researchers to perform chemical and isotopic measurements at previously unattainable scales. However, examination of Table 1 highlights the fact that NanoSIMS analysis has not been applied to nuclear science-related problems to the same degree as it has to other scientific disciplines.

\footnotetext{
${ }^{1}$ NanoSIMS literature summary link: www.cameca.com/literature/scientific-publications/nanosims.aspx.
} 
Table 1. Number of publications containing NanoSIMS data according to various scientific disciplines (Adapted from Horreard 2017).

\begin{tabular}{|l|c|}
\hline \multicolumn{1}{|c|}{ Scientific discipline } & $\begin{array}{c}\text { No. } \\
\text { publications }\end{array}$ \\
\hline $\begin{array}{l}\text { Earth system science: } \\
\text { Geology and environmental science, geochronology, paleobiology and evolutionary studies, } \\
\text { atmospheric particles and aerosols, biomineralization and paleoclimate }\end{array}$ & $\sim 118$ \\
\hline $\begin{array}{l}\text { Planetary science and cosmochemistry: } \\
\text { Nucleosynthesis and evolution of solar system, evolution of planetary bodies }\end{array}$ & $>103$ \\
\hline $\begin{array}{l}\text { Environmental microbiology: } \\
\text { Metabolic pathways, life in extreme environments, biodiversity }\end{array}$ & $\sim 102$ \\
\hline $\begin{array}{l}\text { Cell biology: } \\
\text { Cell metabolism and division, medical applications }\end{array}$ & $\sim 85$ \\
\hline $\begin{array}{l}\text { Materials science: } \\
\text { Batteries, alloys, superconductors, nano-materials }\end{array}$ & $\sim 64$ \\
\hline $\begin{array}{l}\text { Health science: } \\
\text { Cosmetics, pharmacology }\end{array}$ & $\sim 14$ \\
\hline $\begin{array}{l}\text { Plant science: } \\
\text { Nutrient uptake and toxicity, plant structure }\end{array}$ & 27 \\
\hline $\begin{array}{l}\text { Soil science: } \\
\text { Soil composition, soil weathering, soil biology }\end{array}$ & 18 \\
\hline $\begin{array}{l}\text { Nuclear science: } \\
\text { Reactor materials, nuclear waste disposal, nuclear forensics }\end{array}$ & $<10$ \\
\hline
\end{tabular}

Note: There is a lack of published material containing NanoSIMS data in the nuclear sciences. If papers containing data collected on other types of SIMS instruments were included in this category, the number would be significantly higher.

Furthermore, of the approximately 10 published studies (Table 1) where the NanoSIMS has been applied to nuclear materials, there is currently only 1 published study (Kips and Kristo 2009) where a NanoSIMS has been used specifically to address a nuclear forensics-related scientific question.

It is important to note, however, that other SIMS instruments have been used extensively in the field of nuclear forensics, and there is a well-developed body of literature. Section 2.1 provides a brief literaturebased review of the historical development of SIMS analysis in support of nuclear forensics that leads up to a discussion of the current research in the field. Then, in Section 2.2, the strengths (and limitations) of the NanoSIMS 50L are discussed within the context of how this cutting-edge analytical platform might serve the goals of the nuclear forensics research community.

\subsection{LITERATURE REVIEW: SIMS FOR NUCLEAR FORENSIC APPLICATIONS}

The International Atomic Energy Agency (IAEA) was established in 1953 and began a variety of monitoring campaigns shortly thereafter; however, the global importance of a comprehensive nuclear forensics analytical chemistry program was brought to the forefront during the aftermath of the Gulf War, when a network of laboratories (first set up in 1961) collectively managed by the IAEA used a variety of isotopic and chemical techniques to unambiguously demonstrate the nature and extent of clandestine nuclear weapons development activities that had been taking place in Iraq (e.g., Donohue and Zeisler 1993). Although many analytical techniques were applied to material collected in the field, SIMS was not among them. In situations where it was necessary to determine the U-Pu isotopic characteristics of micron-sized particles, thermal ionization mass spectrometry (TIMS) was utilized. To understand the isotope systematics of individual particles using TIMS, each particle must be isolated and loaded individually under ultra-cleanroom conditions using high-purity reagents (refer to summary by Stanley 
et al. 2013). TIMS produces very precise isotopic compositions, but it is a very time-consuming and labor-intensive technique. This limits its application in cases where isotopic data are needed for a large number of small particles within a relatively short time frame.

Although the IAEA's investigation into Iraq's clandestine nuclear activities was successful, program managers directly involved in the endeavor are candid in their assertion that analytical methods capable of producing rapid (yet reliable) results are critically important (e.g., Donohue and Zeisler 1993). The first mention in the literature of SIMS being applied to the detection and isotopic characterization of a micronsized actinide particle of unknown provenance found on an environmental swipe sample was by Tamborini et al. (1998). Before the Tamborini et al. (1998) study, there were few studies presenting SIMS isotope data obtained on actinide-bearing microparticulates, including standard reference materials (SRMs) (e.g., Stoffels et al. 1994). Since the Tamobrini et al. (1998) study appeared, the body of literature discussing SIMS applications for particle analysis in support of nuclear forensics has expanded to approximately 37 peer-reviewed papers (See Appendix A). This number does not include technical bulletins, conference abstracts, or archived presentations available on the internet. These papers form the basis of the discussion that follows in the remainder of this section, but each paper will not be discussed in detail. Instead, the discussion will trace the technique's evolution from the time when the major question was whether the SIMS technique was even suitable for particle analysis in support of nuclear forensics applications to the current situation where SIMS is becoming a central capability in nuclear forensics laboratories (Walther 2011).

\subsubsection{Early days of SIMS nuclear particle analysis and evolution of instrumental methods}

The first reported comprehensive feasibility study aimed at determining whether SIMS could be used for the analysis of actinide microparticles collected during nuclear safeguards-related environmental sampling was by Tamborini et al. (1998). In the Tamborini et al. (1998) study, a Cameca IMS-6f instrument was used to determine the ${ }^{234} \mathrm{U} / 238 \mathrm{U},{ }^{235} \mathrm{U} / 238 \mathrm{U}$, and ${ }^{234} \mathrm{U} / 235 \mathrm{U}$ ratios on microparticles derived from actinide SRMs as well as extracted from a real environmental swipe. Although the IMS-6f is capable of attaining a mass resolving power $(\mathrm{MRP})^{2}$ of $\sim 10,000(\Delta \mathrm{M} / \mathrm{M})$, Tamborini et al. (1998) found that an MRP of only $\sim 1,000$ was needed to resolve the ${ }^{234} \mathrm{U},{ }^{235} \mathrm{U}$, and ${ }^{238} \mathrm{U}$ peaks, allowing them to retain sufficient transmission for performance of a robust analysis on small sample volumes. Ultimately, Tamborini et al. (1998) were able to demonstrate that the IMS-6f could predictably obtain the correct isotopic composition for the SRM particles. In their study, microparticles were mounted on adhesive carbon tabs and coated with a layer of carbon before being introduced into the SIMS instrument, and while Tamborini et al. (1998) were able to reduce the effect of the substrate blank through the application of an energy offset, they noted that further work would be needed to accurately perform the hydride correction (e.g., ${ }^{238} \mathrm{U}^{1} \mathrm{H}$ on ${ }^{239} \mathrm{Pu}$ and ${ }^{235} \mathrm{U}^{1} \mathrm{H}$ on ${ }^{236} \mathrm{U}$ ). Later studies would ultimately demonstrate the importance of the sample substrate in reducing background levels and hydride interferences (Section 2.1.5), but the early work of Tamborini et al. (1998) was instrumental in demonstrating that SIMS could reliably be applied to actinide isotope measurements on microparticles.

As is the case in any scientific discipline involving the analysis of complex materials, the introduction of a new analytical method creates the need to compare its capabilities with the existing methods. Before the application of SIMS to actinide microparticulate isotope analysis, TIMS was used exclusively for this purpose. Therefore, the fact that Tamborini et al. (1998) were able to demonstrate that the correct values for actinide SRMs in microparticulate form could be attained by SIMS was almost immediately followed by the study of Betti et al. (1999), which focused partly on comparison of the results achievable by SIMS with those obtained by TIMS. Although the study of Betti et al. (1999) explored several topics relevant to SIMS actinide microparticle analysis (e.g., the use of image intensity for isotope ratio determination, the

\footnotetext{
${ }^{2}$ Cameca definition of $M / \Delta M$.
} 
effect of analytical substrate on molecular isobar and blank levels, and the use of wide-ranging mass spectrum acquisition to assess the bulk-composition of the microparticle), the ability to consistently obtain SIMS ${ }^{240} \mathrm{Pu} /{ }^{239} \mathrm{Pu}$ ratios within $1 \%-2 \%$ of TIMS values was also demonstrated. Since the ${ }^{240} \mathrm{Pu} /{ }^{239} \mathrm{Pu}$ ratio was obtained for $\mathrm{Pu}$ particles lacking in $\mathrm{U}$, the good agreement between the two techniques did not require the application of a ${ }^{238} \mathrm{U}^{1} \mathrm{H}$ correction to the ${ }^{239} \mathrm{Pu}$ signal, but the agreement was nonetheless an indication that SIMS was going to be a powerful technique for nuclear forensics applications.

The issue of how to correct for the molecular isobaric interference of ${ }^{235} \mathrm{U}^{1} \mathrm{H}$ on ${ }^{236} \mathrm{U}$ and ${ }^{238} \mathrm{U}^{1} \mathrm{H}$ on ${ }^{239} \mathrm{Pu}$ are still topics of active research in the SIMS community (e.g., Esaka et al. 2011; Simons and Fassett 2017), as is the most effective way to produce standards whose results can be realistically applied to unknowns (e.g., Erdmann et al. 2000; Ranebo et al. 2010). Indeed, there are many complexities related to the analysis of actinide microparticles by SIMS that were recognized in the early studies but that have yet to be fully resolved. In the subsections that follow, research and development (R\&D) efforts focused on a variety of topics, including unresolved issues, will be explored. The remainder of this subsection will discuss some overarching concepts related to microparticle analysis by SIMS - namely instrumentation and the primary ion source. The two early studies mentioned in the preceding paragraphs were performed on Cameca IMS-6f instrument with a mass-filtered $\mathrm{O}_{2}{ }^{+}$primary beam. The IMS series Cameca instruments (3f, 4f, 5f, and 6f) are considered "small geometry" SIMS instruments. This term refers primarily to the turning radius of the magnetic sector field, which ultimately affects the relationship between sensitivity and MRP. Although larger geometry SIMS instruments (e.g., the Cameca IMS-1280) are capable of attaining significantly higher MRP and transmission (resulting in greater sensitivity) than the smaller geometry instruments, the IMS-4f, $-6 \mathrm{f}$, and $-7 \mathrm{f}$ instruments are still commonly used for nuclear forensics particle analysis (refer to Appendix A). That said, the larger geometry instruments are increasingly used in this field. There will likely be many studies in the coming years focused on exploiting the high sensitivity capabilities of the larger geometry SIMS instruments.

Lastly, it is important to briefly discuss the importance of the primary ion source. Across the spectrum of SIMS instruments, there are many possible primary ion sources. It is also well recognized that one of the major controlling factors in the production rate of secondary ions during sputtering of any material is the primary ion type. For the purpose of SIMS nuclear particle analysis, a mass filtered oxygen beam (typically $\mathrm{O}^{-}$or $\mathrm{O}_{2}^{-}$) is utilized for actinide analysis. As will be discussed in Section 2.1.2, other primary beams are used for other elements (e.g., a Cs beam for $\mathrm{O}$ isotope analysis and $\mathrm{F}$ content determinations), there has been relatively little research into the use of anything other than $\mathrm{O}^{-}$for the actinide elements. One such study is that of Letho and Liponnen (2003), who experimented with use of a Ga source on a VG IX70S SIMS instrument. Application of the Ga beam to IAEA quality control and round-robin samples demonstrated that their instrument could produce ${ }^{235} \mathrm{U} /{ }^{238} \mathrm{U}$ ratios within error of the "correct" values, which would be sufficient to detect even a $1 \%{ }^{235} \mathrm{U}$ enrichment level. However, while the Letho and Liponnen (2003) study suggests that a $\mathrm{Ga}^{+}$primary beam is suitable for $\mathrm{U}$ isotope analysis, the fact that for nuclear forensics, the most commonly used SIMS platforms are produced by Cameca and are equipped with an $\mathrm{O}^{-}$source as a standard specification, it appears likely that $\mathrm{O}^{-}$will continue to be the dominant primary beam source. This is highlighted by the fact that experiments by Kips and Kristo (2009) using a $\mathrm{Cs}^{+}$beam to measure $\mathrm{U}$ isotope compositions from $\mathrm{U}$ particles did not produce measurable U signals.

\subsubsection{Moving beyond $\mathrm{U}$ and $\mathrm{Pu}$}

For nuclear forensic particle attribution studies, information beyond the actinide isotopic composition is often needed to fully understand the information transferred onto the sampling medium. For example, particle morphology can be a diagnostic tool in determining particle origin and history (e.g., Bowen et al, 2013). For SIMS analysis in support of nuclear forensics, there have been efforts to use the technique to 
determine particle bulk composition (e.g., Betti et al. 1999; Park et al. 2017; Donohue et al. 2008), F content (Kips et al. 2007; Kips and Kristo 2009; Kips et al. 2009), O isotope composition (Tamborini et al. 2002, 2002b; Pajo et al. 2001), and particle age (Faure and Dalger 2017; Wallenius et al. 2001). It is generally well understood that uranium and plutonium oxide particles collected during environmental sampling campaigns can contain impurities that are readily observable using energy dispersive spectroscopy (EDS) or X-ray diffraction (XRD) (e.g., Ranebo et al. 2007; Torok et al. 2004). There is an understanding that these impurities can contribute to elemental and molecular isobaric interferences on the actinide species, but methods capable of simultaneously determining precise trace element concentrations in conjunction (i.e., by multicollection or magnetic peak hoping) with actinide isotope compositions during SIMS microparticle analysis have not yet appeared in the literature.

The early study of Betti et al. (1999) demonstrated that a wide-ranging mass scan could be used to obtain a mass spectrum for actinide particles under oxygen bombardment from which the bulk-chemistry could be deduced. However, such an approach does not provide quantitative bulk or trace elemental data and requires sputtering away some of the particle, which would potentially result in less material available for actinide isotope analysis. This issue is still very much unresolved, as demonstrated by Park et al. (2017) who attempted to combine time of flight (TOF) and dynamic SIMS measurements to obtain particle bulk composition in addition to actinide isotope composition. However, in their study it was necessary to perform the TOF-SIMS bulk-composition analysis on a separate set of particles than those analyzed for their actinide isotope compositions on the IMS-7f instrument. This was largely due to the volume of material consumed during the bulk-composition measurement and the fact that it is difficult to calculate accurate isotope ratios from TOF-SIMS data. At present, the most promising means of determining the bulk and trace elemental composition of single particles to complement SIMS actinide isotope data is to perform the bulk and/or trace element measurement using a nondestructive technique (e.g., EDS or XRD; e.g., Donohue et al. 2008) before the SIMS analysis. For real environmental samples this typically requires isolation of the particle by micromanipulation (e.g., Donohue et al. 2008; Esaka et al. 2007), resulting in an increased processing time that diminishes one of the advantages of the SIMS techniquerapidity.

Several studies (Pajo et al. 2001; Tamborini et al. 2002a, 2002b) have demonstrated that the determination of $\mathrm{O}$ isotope compositions via SIMS in $\mathrm{UO}_{2}$ particles and larger materials is a relatively straightforward endeavor. This is in part because instrumental mass discrimination for $\mathrm{O}$ isotope analysis appears to require very little, if any, matrix-dependent corrections. It is now accepted that $\mathrm{O}$ isotope ratios can be acquired for nuclear particles with precision and accuracy comparable to determinations for silicates, which have very well calibrated SRMs (Pajo et al. 2001; Tamborini et al. 2002a, 2002b). What has not been demonstrated, however, is the coupling of actinide and oxygen isotope composition for the same particle. This is because oxygen isotope analyses must be performed using a positive primary ion beam (e.g., $\mathrm{Cs}^{+}$), whereas an $\mathrm{O}^{-}$primary ion beam is typically used for the actinide isotope analysis. To ensure high precision in a situation where a single material was going to be sputtered with two primary beams in succession (e.g., $\mathrm{O}^{-}$and $\mathrm{Cs}^{+}$), the oxygen isotope data must be collected first to avoid generating a perturbed oxygen isotope signature as a result of $\mathrm{O}^{-}$bombardment. The high spatial resolution ion images and data obtained on the NanoSIMS might allow data sets collected under both primary beams to be aligned, enabling correlation of the oxygen isotope data collected under $\mathrm{Cs}^{+}$bombardment and the actinide isotope data collected under $\mathrm{O}^{-}$bombardment. This topic will be revisited in Sections 2.2 and 5.1.

The use of SIMS to determine the F content of uranyl fluoride $\left(\mathrm{UO}_{2} \mathrm{~F}_{2}\right)$ has been investigated by a number of authors (e.g., Faure et al. 2014; Kips et al. 2007; Kips et al. 2009; Kips and Kristo 2009), who share the goal of integrating the $\mathrm{F}$ concentration and $\mathrm{U}$ isotopic data to determine the history of individual $\mathrm{UO}_{2} \mathrm{~F}_{2}$ particles. The major hurdle has been that $\mathrm{F}$ and $\mathrm{U}$ exhibit drastically different ionization characteristics. Under bombardment with $\mathrm{O}^{-}$(which is necessary to produce $\mathrm{U}$ secondary ions), much of the $\mathrm{F}$ in the 
particles appears to get sputtered away before $U$ secondary ion production attains sputtering equilibrium (e.g., Kips and Kristo 2009). When coupled with the lack of $\mathrm{UO}_{2} \mathrm{~F}_{2}$ particulate standards with wellcalibrated fluorine concentrations, development of a method to quantify the $\mathrm{F}$ content in particles of interest to the nuclear forensics community has remained elusive.

The approach adopted by Kips et al. (2010) is to sputter each $\mathrm{UO}_{2} \mathrm{~F}_{2}$ particle until all the $\mathrm{F}$ disappears, followed by calculation of a $\mathrm{F} / \mathrm{U}$ ratio by integration of the total counts for $\mathrm{F}$ and $\mathrm{U}$ separately. The $\mathrm{F} / \mathrm{U}$ ratios from each particle are then averaged over all the particles in a sample, with the goal of producing an average $\mathrm{F} / \mathrm{U}$ ratio for the sample in question. In theory, this approach is designed to mitigate the relatively unconstrained differences between the ionization efficiency of uranium and fluorine. However, it is dependent on the assumption that all the particles in each sample have the same actual U/F ratio. In practice, however, Kips et al. (2010) report average F/U ratios with very high uncertainties, which suggests that the samples in question may not contain particles with homogeneous $\mathrm{F} / \mathrm{U}$ ratios or the dataprocessing approach is insufficient. This inhibits an assessment of the effectiveness of this approach. A similar problem has been reported by Faure et al. (2014), who was unable to quantify the amount of $F$ in $\mathrm{UO}_{2} \mathrm{~F}_{2}$ particles despite several different approaches to data acquisition and processing.

So far, three methodological developments that have not had much success have been discussed: (1) the determination of bulk and or trace element chemistry, (2) O isotope content in combination with actinide isotope compositions on single particles, and (3) F content in combination with actinide isotope compositions on single particles. There will likely be further investigation into these issues. In contrast, several studies (Wallenius et al. 2001; Faure and Dalger 2017; Tamborini et al. 2002b) report on successful attempts to combine particle radiometric age-dating with actinide isotope fingerprinting during SIMS analysis. Age dating of actinide microparticles relies on accurate determination of the ${ }^{230} \mathrm{Th} /{ }^{234} \mathrm{U}$, ${ }^{238} \mathrm{Pu} /{ }^{234} \mathrm{U},{ }^{239} \mathrm{Pu} /{ }^{235} \mathrm{U},{ }^{240} \mathrm{Pu} /{ }^{236} \mathrm{U},{ }^{241} \mathrm{Pu} /{ }^{241} \mathrm{Am}$, and ${ }^{242} \mathrm{Pu} /{ }^{238} \mathrm{U}$ ratios (e.g., Tamborini et al. 2002b), with the most reliable age constraints arising out of determining ages using multiple parent-daughter systems to identify situations where the primary assumptions needed to reliably interpret the calculated ages (e.g., closed-system behavior, initial amount of daughter product, etc.) are not fulfilled. Another complication arises out of the fact that $\mathrm{Th}, \mathrm{U}$, and $\mathrm{Pu}$ do not possess identical ionization behaviors, so the reality is that appropriate SRMs are needed to obtain relative sensitivity factors (RSFs) that can be applied to the $\mathrm{Pu} / \mathrm{U}$ and $\mathrm{Th} / \mathrm{U}$ ratio determinations. Despite these potential pitfalls, it appears that certain SIMS age measurement techniques can routinely produce the necessary accuracy and precision to verify $\mathrm{Pu}$ production cutoff dates (e.g., ages based on the $\mathrm{Pu} / \mathrm{U}$ ratios; Wallenius et al. 2001), whereas other applications remain elusive (e.g., the age of enriched $\mathrm{U}$ particles not containing Pu based on the ${ }^{230} \mathrm{Th} /{ }^{234} \mathrm{U}$ ratio; e.g., Faure and Dalger 2017).

\subsubsection{Analysis of particles from complex matrices}

Microparticle actinide isotope composition determinations in support of nuclear forensics applications are not limited to particles collected on environmental swipe samples. For example, determining the actinide isotope composition of particles in soils, in spent munitions components, or taken directly from the atmosphere may be necessary in certain situations. To this end, SIMS methods have been developed for actinide particles in war-zone soils (e.g., Danesi et al. 2003; Tamborini and Betti 2000; Torok et al. 2004) as well from weapons materials matrices (e.g., Ranebo et al. 2007). In theory, two possible approaches could be applied to the preparation of particles in a soil matrix for SIMS analysis. One approach would be to attempt to extract the particles of interest so that they could be isolated from their matrix before SIMS analysis, whereas the other would be to simply mount the bulk (or minimally processed) matrix containing the particles of interest followed by an automated search routine to locate the particles of interest before actual actinide isotope ratio measurement. 
For the three studies reporting SIMS data for actinide particles in soil (Danesi et al. 2003; Tamborini and Betti 2000; Torok et al. 2004), only the latter method has been employed. In a sense, this approach is similar to that taken for environmental swipe samples where, with few exceptions (e.g., Esaka et al. 2007), there is no attempt to physically separate the actinide microparticles from the other phases collected on the swipe. While no matrix-related issues specific to the fact that the actinide particles are colocated with the other components in soil, the generally recognized (see discussion by Esaka et al. 2007) analytical issue (e.g., formation of unknown molecular isobars, high background levels, etc.) of sputtering material co-located with the actinide microparticles during SIMS analyses is applicable to these studies. In contrast, Ranebo et al. (2007) developed a method for the isolation of individual "hot particles" from soil contaminated with fissile material as a result of the Thule accident, which involved the crash of a B52 carrying nuclear warheads over Greenland in 1968. Their approach was to employ a repetitive sample splitting regime guided by the ${ }^{241} \mathrm{Am} 59.5 \mathrm{keV}$ gamma line arising from the decay of ${ }^{241} \mathrm{Pu}$ until single particles of interest were obtained. These particles were then further manipulated in preparation for SIMS analysis, a process that, while time-consuming, resulted in SIMS analytical domains containing only the particle to be analyzed. Ranebo et al. (2007) were able to obtain very high precision isotope ratios, which they attributed to their use of a technique to isolate the particles of interest before SIMS analysis. Others (e.g., Esaka et al. 2012; see Section 2.1.4) have employed the use of the fission track technique to identify individual particles of interest, which are then removed and mounted on a clean substrate for SIMS analysis.

\subsubsection{Evolution of workflows and data handling}

The reality of environmental sampling is that the particles of interest typically occur within a matrix dominated by other materials. In some cases, these matrices can be problematic for SIMS analysis because they can form molecular isobaric interferences on the masses of interest (see discussion by Park et al. 2017), but another ubiquitous difficulty arises from simply trying to identify the particles of interest for more targeted SIMS analysis. In this regard, there are three overarching possibilities: (1) Physically isolate the particles from the matrix before SIMS analysis, (2) use a variety of possible techniques before SIMS analysis to identify the location of regions of interest for SIMS analysis, or (3) use the SIMS itself to identify the particles of interest. Each of these possibilities has advantages and limitations, and there has actually been a fair amount of R\&D focused on developing optimized particle recovery, identification, isolation, and workflows.

Esaka et al. (2007) recognized that deviation of the ${ }^{234} U / 238 U$ and ${ }^{236} U / 238 U$ ratios from the accepted values for several SRMs was associated with an increase in the count rate of ${ }^{208} \mathrm{~Pb}$. Further testing, and eventual confirmation of the idea that the presence of $\mathrm{Pb}$ (which is common for swipes collected in industrial settings) leads to molecular isobaric interferences, led Esaka et al. (2007) to develop a particle handling workflow aimed at producing SIMS mounts containing actinide particles of interest that were completely isolated from any possible interfering phases. Esaka et al. (2007) prepared a series of mixed dispersions of powdered $\mathrm{Pb}$ metal and actinide microparticulate SRMs, and then used a gold-tipped needle to transfer individual SRM particles onto a clean planchet. The key was that this was done within the vacuum chamber of an SEM using secondary electron imaging to guide the particle transfer in real time. This method was capable of producing isolated actinide particles and was tested on a real environmental swipe sample, but it is time-consuming. Despite the high time requirement, this single particle method has been used in a few studies (e.g., Esaka et al. 2008; Tarolli et al. 2016) since its development.

In contrast to efforts aimed at producing isolated actinide particles for SIMS analysis (e.g., Esaka et al. 2007), which adds time to the sample processing stages leading up to SIMS analysis, another area of considerable R\&D effort has been focused on the development of automated workflows for particle identification and analysis. Although the approach of identifying particles of interest using an EDS-based 
scanning regimen before SIMS analysis is well entrenched (see discussion by Hedberg et al. 2011), there has been great interest in developing protocols whereupon particle recognition and analysis is performed on the SIMS within the context of a single automated workflow (e.g., Willingham et al. 2016; Peres et al. 2012; Hedberg et al. 2011). The technique usually involves rastering a high intensity primary beam over a large area, followed by the automatic selection (typically based on an isotope ratio threshold) and focused analysis of regions of interest. Such techniques are proving capable of identifying and analyzing particles with great efficiency and speed, but they do not eliminate issues associated with background contributions from material collocated with the particles of interest. It is noteworthy that actinide microparticle standards are being designed for the specific purpose of testing the efficacy of automated identification and analysis routines (e.g., Wellons et al. 2017).

Current R\&D efforts are also focused on the development of automated software protocols aimed at reconciling data collected via XRD or SEM with SIMS (e.g., Tarolli et al. 2016) to spatially resolve actinide isotope composition with other chemical signatures at the single-particle scale. One potential

pitfall associated with the use of automated particle recognition and location software guiding the location of SIMS analysis is that particles can be missed. A similar problem can be encountered during manual particle searches - even the most thorough searches can sometimes overlook small particles or those obscured by matrix material. To circumvent the issue, particle recognition protocols based on the development of induced fission tracks (e.g., Esaka et al. 2012) or natural alpha tracks (e.g., Esaka and Magara 2014) in material placed in close proximity to the sample have been developed. These methods do result in a means of easily identifying particles of interest (e.g., those containing U), but it takes time to use of a variety of reagents and mounting mediums, some of which require ashing before SIMS analysis (e.g., Esaka et al. 2012), as well as time to induce fission tracks in a reactor, or for alpha tracks to manifest themselves. This must all be considered if the goal is to minimize the time required to process and analyze samples brought back from the field.

\subsubsection{Understanding the effects of analytical substrate}

Examination of Appendix A, a compilation/summary of existing SIMS nuclear forensics particle analysis protocols, reveals that there are a wide variety of approaches to preparing a sample collected in the field for SIMS analysis. However, the process invariably culminates with transferring the particles onto a conductive substrate (e.g., a carbon planchet, silicon wafer, or metallic foil) before introduction into the SIMS instrument. This step is essentially a requirement, as a conductive surface is necessary - that is, it would be impossible to analyze the particles by SIMS if they were still adhered to the environmental swipe material. The first study presenting SIMS actinide isotope data on unknown microparticles within a nuclear forensics research scope (Tamborini et al. 1998) recognized that the analytical substrate can influence the SIMS measurement in several ways: (1) Production of an elevated background signal, (2) production of elemental and molecular species that will complex with those generated from the particle itself and produce isobaric interferences on the masses of interest, and (3) effect the ionization efficiency of the target elements. These issues are mentioned in a variety of studies (see the sixth column of Appendix A), but there are relatively few studies that take a systematic approach to identifying and correcting them.

A recent study by Sharp et al. (2016) investigated $\mathrm{U}^{+}, \mathrm{UO}^{+}$, and $\mathrm{UO}_{2}^{+}$secondary ion production from uniformly sized uranium oxide microspheres as a function of different substrates (graphite planchets and silicon wafers) and primary ion beams $\left(\mathrm{O}^{-}, \mathrm{O}_{2}^{-}\right.$, and $\left.\mathrm{O}_{2}^{+}\right)$. Although Sharp et al. (2016) documented differences in the apparent ionization efficiencies of the $U$ species across the different substrates and primary beams, their conclusion was that most differences could be accounted for as part of a robust RSF determination procedure during analysis of unknowns. However, Sharp et al. (2016) also documented behavior (e.g., a sudden change in secondary ion intensity) when analyzing particles on silicon wafers under certain primary beam conditions that would not be easy to incorporate into a data processing 
regime. Sharp et al. (2016) concluded that a change in the local matrix had occurred around the particles on silicon during primary ion bombardment. Furthermore, they postulated that this change involved the production of $\mathrm{SiO}_{\mathrm{x}}$, meaning that additional complexing could occur during the analysis of an unknown particle containing impurities not found within the pure standards they were working with. This is potentially problematic for nuclear forensics applications because silicon wafers are commonly used as a collection media and analytical substrate and highlights the need for additional research in this area.

Examination of Appendix A reveals that there are (1) several substrates used for SIMS particle analysis in support of nuclear forensics applications and (2) a variety of methods for removing the particles from the collection matrix and then transferring them onto the analytical substrate. In many cases, this involves the use of a solvent that can, at least theoretically, be totally evaporated before SIMS analysis. However, in some cases a solvent-adhesive mixture is used so that the adhesive will resist evaporation and keep the particles adhered to the surface of the substrate during SIMS analysis, help prevent the clumping of multiple particles that is known to occur during solvent evaporation, or a combination of both actions (e.g., Torok et al. 2004; Esaka et al. 2012; Faure et al. 2014; Faure and Dalger 2017). There are currently no studies that take a systematic approach to evaluating whether residual solvent or adhesive influences the background levels, formation of elemental or molecular isobars, or ionization efficiency of the species of interest.

Another relatively common method of transferring material from environmental swipe samples onto the SIMS analytical substrate is vacuum impaction (e.g., Faure et al. 2014; Hedberg et al. 2011; Esaka et al. 2007 \& 2009; Faure and Dalger 2017; Faure et al. 2014; Park et al. 2017; Ranebo et al. 2010). Vacuum impaction is sometimes known to result in low particle recovery efficiency because many of the particles removed from the swipe may not remain electrostatically adhered to the analytical substrate (typically a carbon planchet). Therefore, some researchers have adopted the approach of coating the substrate with an adhesive substance (e.g., Faure et al. 2014; Faure and Dalger 2017) or grease (Esaka et al. 2004 \& 2007b; Park et al. 2017) or transferring the particles onto an adhesive medium (e.g., carbon tape; Ranebo et al. 2010) by vacuum impaction.

Esaka et al. (2004) performed a series of experiments to determine the effect of grease coating on the transfer of particles by vacuum impaction from swipe samples onto a silicon wafer for SIMS analysis. Averaged across 16 swipe samples, they found that an average of $49 \%$ of particles on the swipe were effectively transferred onto the grease-coated wafer by vacuum impaction, whereas the average effective transfer rate for uncoated wafers was only 5\%. Furthermore, they found that application of the grease layer to silicon wafer actually reduced the blank signal at masses 236, 237, and 238 in comparison to an uncoated wafer. They attributed this observation to the possibility that the grease acted to suppress the formation of $\mathrm{SiO}_{\mathrm{x}}$ cluster ions during $\mathrm{O}^{-}$bombardment. However, Esaka et al. (2009) also observed a relatively strong signal at mass 239 , and because the sample contained no $\mathrm{Pu}$, they attributed this to the formation of ${ }^{238} \mathrm{U}^{1} \mathrm{H}$ from a reaction between $\mathrm{U}$ in the sample and $\mathrm{H}$ from the hydrocarbon component of the grease. Therefore, the grease-coating approach serves to increase the effective particle yield and can lead to the suppression of molecular isobars interfering on certain $U$ masses, but it would be difficult to develop a correction of the measurement of ${ }^{239} \mathrm{Pu}$ in U-bearing particles. This difficulty highlights the fact that there is likely to be no uniformly applicable solution to particle handling; essentially, each approach has its limitations and advantages and must be tailored to the specific objects of the SIMS measurement.

\subsubsection{Are there techniques better than SIMS?}

Although SIMS inarguably has certain advantages for the analysis of microparticles in support of nuclear forensic investigations, namely the ability to relatively rapidly produce accurate actinide isotope data at the single-particle scale, the question of whether other techniques might be more effective has been raised. One difficulty with SIMS actinide measurement is in the determination of accurate ${ }^{234} \mathrm{U} /{ }^{238} \mathrm{U}$ and 
${ }^{236} \mathrm{U} /{ }^{238} \mathrm{U}$ ratios due to the formation of molecular isobaric interferences on the already low-abundance isotopes ${ }^{234} \mathrm{U}$ and ${ }^{236} \mathrm{U}$. Although a variety of correction regimes for SIMS analysis have been developed (see discussion by Simons and Fassett 2017), there is no way to totally suppress the formation of interfering species. This becomes an even greater issue in the case of particles containing elemental impurities, because these can have an unconstrained influence on the ionization efficiency of the species of interest in addition to producing interfering species. Esaka et al. (2009) proposed a new method for the determination of actinide isotope compositions that attempts to circumvent the formation of interfering species inherent to SIMS analysis but that is not plagued by the long processing times associated with TIMS single particle determinations. The approach of Esaka et al. (2009) is to isolate single microparticles and then digest them in a small volume of ultraclean $\mathrm{HNO}_{3}$. This solution is then diluted such that it can be introduced directly into a desolvating nebulizer system coupled to an inductively coupled plasma-mass spectrometer (ICP-MS). Esaka et al. (2009) were able to demonstrate that the ICPMS-based approach can produce ${ }^{235} \mathrm{U} / 238 \mathrm{U}$ ratios with accuracy and precision comparable to SIMS, whereas the ICP-MS outperformed the SIMS for the determination of ${ }^{234} U /{ }^{238} U$ and ${ }^{236} U / 238 U$ ratios.

The single particle ICP-MS approach proposed by Esaka et al. (2009) may have another advantage over SIMS in that it would be relatively straightforward to introduce a chemical separation step into the workflow. Esaka et al. (2011) attempted to apply the ICP-MS approach to the determination of $\mathrm{U}$ and $\mathrm{Pu}$ isotope composition of a mixed uranium-plutonium oxide particle standard. The analysis of Pu isotope compositions by SIMS suffers from molecular isobaric interferences in the same way as the U isotope determinations (e.g., ${ }^{238} \mathrm{U}^{1} \mathrm{H}$ impinges on ${ }^{239} \mathrm{Pu}$ ), but is also plagued by the fact that ${ }^{241} \mathrm{Am}$ interferes on ${ }^{241} \mathrm{Pu}$. Esaka et al. (2011) found that determining the ${ }^{235} \mathrm{U} /{ }^{238} \mathrm{U},{ }^{240} \mathrm{Pu} /{ }^{239} \mathrm{Pu}$, and ${ }^{242} \mathrm{Pu} /{ }^{239} \mathrm{Pu}$ ratios using their ICP-MS approach was not complicated (albeit the ratios are not fully corrected for the interference of ${ }^{238} \mathrm{U}^{1} \mathrm{H}$ on ${ }^{239} \mathrm{Pu}$ ). Because Esaka et al. (2011) was unable to fully constrain the magnitude of the ${ }^{238} \mathrm{U}^{1} \mathrm{H}$ isobaric interference on ${ }^{239} \mathrm{Pu}$, which is also an issue during SIMS Pu isotope analysis, it is unclear whether the ICP-MS technique provides an advantage over SIMS for the determination of these specific ratios. However, they found that chemical separation of $\mathrm{U}, \mathrm{Pu}$, and $\mathrm{Am}$ would enable them to determine the ${ }^{241} \mathrm{Pu} /{ }^{239} \mathrm{Pu}$ ratio. Such a separation step would only be able to be incorporated into the ICP-MS workflow, so in this regard, the ICP-MS-based approach does appear to have a potential advantage over SIMS. However, for more routine applications in nuclear forensic particle analysis (e.g., the determination of the ${ }^{235} \mathrm{U} /{ }^{238} \mathrm{U}$ ratio), SIMS retains the clear advantage over ICP-MS because of its reliability and rapidity.

\subsection{HOW DOES THE NANOSIMS 50L FIT INTO THIS LANDSCAPE?}

Based on the literature pertaining to the determination of actinide isotope compositions of microparticles in support of nuclear forensics research (Section 2.1.1), it is clear that there are several overarching problems that have yet to be fully resolved:

1. How to prepare particles for analysis in a manner that suppresses the formation of molecular isobars?

2. How to develop correction schemes for molecular and elemental isobars that cannot be mitigated through appropriate sample preparation?

3. How to ensure that automated particle identification and analysis regimes are producing representative data sets?

4. How to understand how impurities within the particles affect the ionization efficiency of the species of interest?

5. How to determine actinide isotope composition and other chemical information on the same regions of interest (e.g., O isotopes or F content)? 
As explained above, promising avenues for future investigation, and even resolution, of these questions exist. At this point it is worthwhile to consider how the NanoSIMS, one of Cameca's newer SIMS platforms, might help to address some of these questions.

As explained in the introduction of this document, the NanoSIMS instrument is distinguished by its capability to perform chemical and isotope measurements with sub-micron resolution. The size range of actinide-bearing microparticles collected during nuclear forensics environmental sampling campaigns commonly ranges into the sub-micron level (e.g., Esaka et al. 2008) and may contain chemical heterogeneities (e.g., Donohue et al. 2008), so the notion that the NanoSIMS's small primary beam footprint could provide a way to obtain a more focused analysis on smaller particles, thus reducing the background signal from the substrate, is relatively straightforward. However, the latest generation of the NanoSIMS instrument, which is the 50L model acquired by ORNL, possess some unique capabilities beyond small primary beam spot footprint that may contribute to advances in the field of nuclear forensics.

Specific nuclear forensics projects that could be undertaken as part of the commissioning process (or thereafter, for that matter) are described in Section 5.1; however, it is also appropriate to highlight some of the possible research areas where the latest-generation NanoSIMS instrument could provide significant advances. Beyond the capability to produce small primary beams, the NanoSIMS 50L instrument at ORNL is equipped with the newly developed Hyperion radiofrequency plasma $\mathrm{O}^{-}$source to complement the $\mathrm{Cs}^{+}$source. Compared to duoplasmatron, which is the standard $\mathrm{O}^{-}$source on most other SIMS instruments (both large and small geometry), the Hyperion source requires little routine maintenance, can produce a stable $\mathrm{O}^{-}$primary beam almost immediately upon starting, and does not require a long cooldown or pump-out time once it is turned off. This means that it is theoretically possible to switch between source polarities more rapidly and easily than on the other instruments, effectively making it possible to interrogate materials using both ion sources in relatively rapid succession (e.g., O isotopes or F content with the $\mathrm{Cs}^{+}$source followed by actinides with the $\mathrm{O}^{-}$source relatively rapidly), whereas on other instruments with the duoplasmatron source, such an approach would be more time-consuming.

There are some other unique attributes of the NanoSIMS 50L (e.g., rapid-switching between electron multiplier and Faraday cup detectors), but it is unclear how they might be applied to nuclear forensics questions. Instead, it is important to mention a possible limitation of the NanoSIMS 50L. The analysis chamber of the NanoSIMS 50L is operated at a vacuum level that is an order of magnitude higher than the other SIMS instruments (e.g., vacuum levels in the low-to-mid $10^{-10}$ mbar vicinity as opposed to the mid $10^{-9}$ mbar on the latest generation IMS-1280 instruments). For the NanoSIMS, maintaining this level of vacuum in the analysis chamber is needed to avoid arcing on the coaxial lens assembly. This vacuum level requirement limits the type of samples that can be introduced into the instrument in a variety of disciplines and may also be limiting in nuclear forensic applications. For example, the use of certain greases, adhesives, or solvents to aid in particle retention and spacing on the analytical substrate might require further investigation before use in the NanoSIMS.

\section{INTERNAL TECHNICAL PROFICIENCY METRICS}

The purpose of this section is to establish metrics and benchmarks that demonstrate that the ORNL NanoSIMS 50L and its supporting scientists can successfully perform analyses relevant to a wide range of scientific disciplines in a manner that is consistent with the instrument's strengths and limitations. This section will also identify the physical materials needed to establish these benchmarks. This part of the commissioning phase (Figure 1) will commence once the Cameca ${ }^{\circledR}$ installation technician has successfully demonstrated all the measurements specified in the installation and acceptance document (e.g., once ORNL has accepted the instrument as fully functional on-site according to the factory specifications). On the recommendation of the Cameca NanoSIMS product developer, the primary users 
should spend the first- 2-3 months on silicon isotopes to become familiar with the instrument software and hardware before pursuing the advanced training. The ORNL SIMS scientists will then demonstrate their ability to reproduce a subset of the measurements and specifications demonstrated as part of the onsite acceptance process. This will set the stage for the ORNL NanoSIMS laboratory to be ready to participate in round-robin style SRM inter-laboratory analytical comparisons while also focusing on performing measurements that have been successfully demonstrated in other labs.

\subsection{DEMONSTRATION OF CAMECA® NANOSIMS FACTORY/INSTALLATION SPECIFICATIONS BY PRIMARY USERS}

The following measurements and specifications will be demonstrated in the same manner as the Cameca engineers on the materials provided by Cameca (copper grid pressed on aluminum matrix, grooved silicon test sample, gold-coated quartz sample, and five silicon wafers).

\subsubsection{Tune instrument to achieve greatest transmission at highest MRP}

- At least 55\% transmission at MRP greater than $6,000(\Delta \mathrm{M} / \mathrm{M})$

- At least $25 \%$ transmission at MRP greater than 9,000 $(\Delta \mathrm{M} / \mathrm{M})$

\subsubsection{Beam diameter metrics}

- Demonstrate $\mathrm{Cs}^{+}$beam diameter approaching $100 \mathrm{~nm}$ with primary current $>2 \mathrm{pA}$

- Demonstrate $\mathrm{Cs}^{+}$beam diameter approaching $50 \mathrm{~nm}$ with any primary current

- Demonstrate $\mathrm{O}^{-}$beam diameter approaching $100 \mathrm{~nm}$ with primary current $>2 \mathrm{pA}$

- Demonstrate $\mathrm{O}^{-}$beam diameter $<50 \mathrm{~nm}$ with any primary current

\subsubsection{Reproducibility of silicon isotope ratios $\left({ }^{29} \mathrm{Si} /{ }^{28} \mathrm{Si}\right.$ and $\left.{ }^{30} \mathrm{Si} /{ }^{28} \mathrm{Si}\right)$ measurements on electron multipliers}

- 10 measurements in one crater of $4 \times 4 \mu \mathrm{m}: 1 \sigma<0.125 \%$

- 16 craters of $4 \times 4 \mu \mathrm{m}$ within an $8 \mathrm{~mm}$ square: $1 \sigma<0.125 \%$

- $6 \times 2$ measurements in beam deflection mode in a $35 \times 35 \mu \mathrm{m}$ field: $1 \sigma<0.14 \%$

- 12 measurements across five different sample-holder holes: $1 \sigma<0.165 \%$

\subsubsection{Reproducibility of silicon isotope ratios $\left({ }^{29} \mathrm{Si} /{ }^{28} \mathrm{Si}\right.$ and $\left.{ }^{30} \mathrm{Si} /{ }^{28} \mathrm{Si}\right)$ measurements on Faraday cups}

- 10 measurements on separate $10 \times 10 \mu \mathrm{m}$ craters (20 $\mu \mathrm{m}$ spacing): $1 \sigma<0.045 \%$

- 16 measurements on separate $10 \times 10 \mu \mathrm{m}$ craters within an $8 \mathrm{~mm}$ square: $1 \sigma<0.06 \%$

- $6 \times 2$ measurements across five different sample holder holes: $1 \sigma<0.08 \%$

\subsubsection{Oxygen isotope ratio $\left({ }^{18} \mathrm{O} /{ }^{16} \mathrm{O}\right)$ reproducibility on Faraday cups}

- 10 measurements on separate $10 \times 10 \mu \mathrm{m}$ craters (20 $\mu \mathrm{m}$ spacing): $1 \sigma<0.08 \%$

- 16 measurements on separate $10 \times 10 \mu \mathrm{m}$ craters within an $8 \mathrm{~mm}$ square: $1 \sigma<0.1 \%$

\subsubsection{A caveat}

An important note is that these specifications require the instrument to be operating completely free of any electronic, mechanical, or software problems and for the instrument's environment to be totally free of instabilities (e.g., temperature, vibrations, or electrostatic/electromagnetic). Due to the complexity of 
the system, this is not always the case. It is also possible to produce high-quality data while the instrument is in a condition that may prevent the attainment of all the factory specifications at any one point in time. Therefore, demonstrating the specifications will not take precedence over the development of methods relevant to sponsor needs, which will lead to the publication of papers in the academic literature. Because any application of the instrument to a scientific question will invariably result in the analysis of SRMs, it will also be possible to judge user proficiency (as gauged by the generation of results from SRMs that are consistent with those produced in other NanoSIMS labs) by looking at the scientific outputs of the laboratory. Therefore, one aspect of the commissioning phase will be the demonstration of factory specifications by the primary users, this will not be the only metric of proficiency.

\section{IMPLEMENTATION OF ANALYTICAL METHODS RELEVANT TO SPONSOR NEEDS}

\subsection{PREPARATION AND ANALYSIS OF U-SERIES STANDARDS}

The Certified Reference Material (CRM) U-series samples are a useful resource for testing the performance of the NanoSIMS instrument. Initially, samples already available in the laboratory will be used to acquire data, and this will proceed in parallel with preparing other U-series samples.

\subsubsection{Samples present in the NanoSIMS laboratory}

Currently there are two prepared $U$ dispersion samples available in the NanoSIMS laboratory for analysis. CRM U-500 and a natural U sample will be used to validate instrument and operator performance. An analysis protocol for measurements of the $\mathrm{U}$ isotopes will be developed and tested. The initial analyses will focus on ${ }^{235} \mathrm{U}$ and ${ }^{238} \mathrm{U}$ ratios to determine precision and accuracy of these measurements. The analysis of the minor isotopes ${ }^{234} \mathrm{U}$ and ${ }^{236} \mathrm{U}$ will be added as a metric once the validity of major isotope measurements has been established.

\subsubsection{Prepare dispersions of $U$ series samples}

Other U series CRMs will be useful as analogues to real-world samples. Building up a suite of references with a range of major and minor isotope abundance will allow us to demonstrate the ability to make accurate measurements across a range of enrichments, providing end users confidence in the results. The suggested CRMs to start with are as follows (see Table 2):

- U200 for one dispersion

- U010 for one dispersion

- $\quad \mathrm{U} 030$ for one dispersion

- Mixed dispersion of U010 and U030

These samples will be used to determine the reproducibility of minor isotope measurements and determine the lower detection limits of the U series samples in the NanoSIMS. The mixed dispersion will create a sample similar to past round-robin samples that have been sent out to the network of labs. Results from the mixture will demonstrate the ability to distinguish two distinct populations that are similar in composition, which is a very important issue in nuclear forensics. A mixed sample more effectively mimics a real-world situation, especially if there has been an attempt to mask one isotopic population by distributing a different isotopic population in the collection area. 
Table 2. Proposed U-series reference material to be used in the NanoSIMS laboratory.

\begin{tabular}{|l|l|}
\hline \multicolumn{1}{|c|}{ CRM } & \multicolumn{1}{c|}{ Purpose } \\
\hline U200 & Reasonable amount of both ${ }^{234} \mathrm{U}$ and ${ }^{236} \mathrm{U}$ for centering the correct peaks during setup \\
\hline U010 & $1 \%$ enriched and approximately equal amounts of ${ }^{234} \mathrm{U}$ and ${ }^{236} \mathrm{U}$ \\
\hline U030 & $3 \%$ enriched and significantly more ${ }^{234} \mathrm{U}$ and less ${ }^{236} \mathrm{U}$ than CRM-010 \\
\hline U010 and U030 & $\begin{array}{l}\text { Mixture of two materials with close but not overlapping composition to test instrument } \\
\text { performance }\end{array}$ \\
\hline U500 & Enriched sample to test instrument performance and center peaks \\
\hline
\end{tabular}

\subsection{RADIOGENIC ISOTOPE RATIO MEASUREMENTS RELEVANT TO NUCLEAR FORENSICS}

The decay of radioactive parent isotopes to the daughter isotopes is used as a chronometer to determine the time elapsed since the chemical system became isolated. The amount of ingrowth of the radiogenic daughter products provides insight into the timing of chemical purification activities at nuclear sites (see recent discussion in Faure and Dalger 2017). One of the goals of measuring minor isotopes is to determine the practical limitations of the NanoSIMS to measure low abundance trace radiogenic daughters.

\subsection{UNDERSTANDING FACTORS THAT AFFECT RESULTS}

\subsubsection{Spatial resolution versus analytical precision and accuracy in particle analysis}

Depending on the questions that need to be answered in any study, there will be a trade-off between spatial resolution and precision of the results. Certain projects will require high spatial resolution to look for changes in isotopic composition during particle growth. High spatial resolution corresponds to a small primary beam - small in both size and intensity. As the intensity of the primary beam current is reduced, the secondary ion yield and thus precision is reduced. Through a series of test measurements on SRMs, we will develop an understanding of the relationship between spatial resolution and precision. This will give us the knowledge of the minimum beam size that can be used to achieve the desired precision on the minor isotopes.

\subsubsection{Understanding the effects of substrate on measurements}

There is not yet a clear consensus in the literature about whether the substrate medium affects the ionization of sample particles on varying substrates. To understand any issues relevant to program needs, a series of test measurements will be made on the NanoSIMS to verify for ourselves any possible matrix effects on isotopic ratios. Using the SRM U-series, we will compare the same samples on the following substrates:

- Carbon planchettes

- Silicon wafers

- Aluminum stubs

- Carbon gun shot residue stubs

The results of these studies will put us in a position to make sound judgements about sample preparation techniques best suited to optimize results. 


\subsubsection{Understand matrix effects}

It has long been known that the matrix composition affects the secondary ion yield for any element. Because of those effects, a measurement of any particular isotope cannot be directly compared across compounds of different compositions without a correction to the data. We propose developing a study to look at a range of uranium compounds to understand the differences in ionization efficiency between different matrices.

\subsection{STABLE ISOTOPE RATIO MEASUREMENTS}

Stable isotopes will be used to support sponsor needs as well as academic studies in other fields such as geology and biology. Therefore, the following section is also applicable to the proficiency and publication discussion in Section 5.

Oxygen isotope composition has been used as a tool for determining sample provenance across multiple disciplines including geology, biology, and environmental science. For instance, to trace the manufacture point of biological agents, the oxygen isotope composition is routinely measured to give an indication of the region where the sample was manufactured. The use of oxygen isotopes in nuclear forensics is becoming more widespread. To be prepared to measure oxygen isotopes, a protocol must be developed to determine the optimum instrument conditions for NanoSIMS measurements. This will be achieved using oxygen SRM's and U-series samples as surrogate test samples. Other stable isotopes such as C, N, and Si can also provide clues about where the sample was manufactured and the processes used to make the sample.

Measuring lithium isotopic composition is of great importance in the nuclear forensics community because of the use of ${ }^{6} \mathrm{Li}$ to boost the yield of a nuclear weapon. There are a few different Li reference materials available, and it will be advantageous to use as many different Li compounds as practical when developing a protocol for measurements.

\section{DEMONSTRATION OF PROFICIENCY TO THE SCIENTIFIC COMMUNITY AND POSSIBLE PUBLICATIONS}

This section explains the final phase of the commissioning plan, which is to conduct scientific studies using the ORNL NanoSIMS 50L that serve to showcase the instrument and operator capabilities to sponsors and the broader scientific community. This will primarily be achieved through the publication of peer reviewed journal articles containing data collected on the ORNL NanoSIMS 50L. The goal will be to publish articles across the range of scientific disciplines to which the NanoSIMS technique has already been applied. However, the practical path forward will be to first focus on basic scientific problems that are within the scope of the operator's scientific expertise. There will also be an emphasis on projects that are specifically relevant to sponsor needs. Branching out into other scientific disciplines will require establishing collaborations. This introduces an element of uncertainty into the proposed timeline for this aspect of the commissioning phase. Therefore, metrics of success for this aspect of the commissioning will primarily be based on publication of data that falls within the operator's disciplinary expertise and the development of protocols specifically relevant to sponsor needs.

\subsection{STUDIES IN NUCLEAR FORENSICS}

As can be seen in Table 1 and gleaned from Section 2 of this document, there are relatively few published studies in the field of nuclear forensics that present NanoSIMS data. There are a larger number of studies making use of SIMS data from other instruments (e.g., the IMS-1280 or 7f), but the NanoSIMS has yet to be extensively utilized in this regard. Based on ongoing discussions with other members of the NSAT 
group, several possible project types related to U-chemistry have been devised. One type of project would be to use isotopically labeled $\mathrm{O}$ in $\mathrm{UO}_{2} \mathrm{~F}_{2}$ synthesis experiments to better understand whether the $\mathrm{O}$ isotope composition of $\mathrm{UO}_{2} \mathrm{~F}_{2}$ can be used as a provenance indicator. Another type of project would be to take advantage of the NanoSIMS sample exchange system (multiple vacuum chambers that can be isolated from one another) to study oxidation reactions on the surface of U-metal. A third type of project would be to use the NanoSIMS for method development aimed at overcoming analytical difficulties with determining the $\mathrm{F}$ content of $\mathrm{UO}_{2} \mathrm{~F}_{2}$ particles collected in the field. Because these possible projects are in sensitive subject areas, specifics will not be discussed in this document. Only studies based on recognized problems within the published nuclear forensics literature will be discussed here (see Section 2 for literature review).

Secondary ion production during SIMS analysis varies greatly between different elemental and molecular species, matrices, and primary ion sources. Therefore, quantitative SIMS analysis is dependent on the extent these differences can be constrained and accounted for in converting measured secondary ion intensities into the actual concentration of the species of interest within a particular material. This is typically accomplished through the determination of RSFs for the analytes of interest by repeated analysis of SRMs whose matrices are matched to those of the unknowns. Equally important for quantitative analysis is the ability to resolve molecular and elemental isobars from the species of interest, which is also partly dependent on having appropriate SRMs such that the veracity of the interference correction can be independently monitored. While the determination of RSFs and interference corrections for certain elemental and isotopic systems within certain matrices are relatively straightforward, other systems pose significant challenges. Nuclear forensics attribution studies, where the goal is to relate the elemental and isotopic characteristics micron-sized particles to specific reaction pathways, fuel-cycle production steps, and/or provenance are one such example. This document outlines some possible R\&D activities with the goal of developing a better understanding of ionization efficiency and matrix effects for species of interest within the types of materials applicable to nuclear forensics particle attribution studies.

\subsubsection{R\&D possibilities related to determining the fluorine content of $\mathrm{UO}_{2} \mathrm{~F}_{2}$}

As discussed in literature review Section 2.1.2, it will not be possible to independently verify an RSFbased approach for $\mathrm{F} / \mathrm{U}$ ratio determination until a particulate $\mathrm{UO}_{2} \mathrm{~F}_{2} \mathrm{SRM}$ of known fluorine content is produced (which itself is challenging). An alternative approach might be to examine the effect of purposefully varying the primary beam intensity between $\mathrm{UO}_{2} \mathrm{~F}_{2}$ particles in a sample that is assumed to contain homogeneous $\mathrm{F} / \mathrm{U}$ ratios. The rationale for this approach would be that because the apparent $\mathrm{F} / \mathrm{U}$ ratio for a given particle may, in fact, be an analytical artifact related to the drastically different ionization behavior of uranium and fluorine, purposefully varying the primary beam intensity across many different particles in a sample might allow for a determination of the magnitude of this analytical artifact. In theory, a population of particles with uniform $\mathrm{F} / \mathrm{U}$ ratios would be expected to develop along an array on a plot of apparent $\mathrm{F} / \mathrm{U}$ ratios as a function of primary beam intensity, in which case a regression through the array would yield the true F/U ratio for the population. In such an approach, the method of Kips et al. (2010) could be used to determine the F/U ratio for individual analyses (with the exception that the particle would be sputtered for a set amount of time), but these values would then be plotted as a function of primary beam intensity.

Although the best-case scenario for quantitative SIMS analysis is to have SRM materials with matrices identically matched to the unknown materials in question, this is not always possible. Even where there is a bulk-matrix match, subtle differences in trace element concentration, structure between the SRM and the unknown material, or both can result in different ionization behavior. Because of this well recognized phenomenon, studies seeking to relate the secondary ion production efficiency between two species to other parameters (e.g., electron affinity or ionization potential; Wilson and Novak 1991; Morgan 1980) have been performed. Most of these studies are application specific (e.g., determining dopant 
characteristics in semiconductors), but have shown that it is often possible to relate the RSF between two elements to their intrinsic chemical properties. In contrast to F and other elemental species for which no relevant reference materials exist, there is not an urgent need to develop alternative analytical approaches for $\mathrm{U}$ and $\mathrm{Pu}$ isotopic determinations. This is because suitable standards for uranium and plutonium analysis in materials relevant to the nuclear fuel cycle already exist and are in routine use by the SIMS community.

However, the approach of utilizing intrinsic chemical properties to determine an RSF between two elements may be a valid avenue in mitigating the drastic differences in ionization behavior between fluorine and uranium that have hampered an accurate determination of $\mathrm{F} / \mathrm{U}$ ratios in particles of interest to nuclear forensics. Because there are a variety of geologic and synthetic materials containing known (or independently verifiable) uranium and fluorine concentrations, an experimental approach would be to determine their concentrations via SIMS and then test whether the RSF between uranium and fluorine can be modeled as a function of their intrinsic chemical properties. In a situation where the behavior is consistent across a variety of matrices, it would then be relatively straightforward to apply this knowledge to the determination of the $\mathrm{F} / \mathrm{U}$ ratio in $\mathrm{UO}_{2} \mathrm{~F}_{2}$.

\subsubsection{R\&D possibilities related to matrix effects of $U^{+}$secondary ion production}

As discussed in Section 2.1, SIMS analysis of U-bearing particles is typically accomplished by transfer of particles collected on environmental swipes onto a substrate that can be introduced into the SIMS instrument. This substrate typically consists of either pyrolytic graphite or polished carbon, a silicon wafer, or platinum foil (Appendix A). Following the transfer of material from the swipe onto the substrate, U-bearing particles are located using a variety of means (e.g., typically by secondary electron microscopy or through use of a particle recognition program on the SIMS) followed by analysis in which the primary ion beam is focused onto the individual particle under scrutiny.

Even in cases where a static primary beam is used, the small size of the particles in question typically results in primary ion beam impingement onto the substrate upon which the particles have been placed for analysis. Therefore, the substrate itself becomes a part of the matrix-related effect on $\mathrm{U}^{+}$secondary ion production. Additionally, impurities comingled with the particles, as well as those present within the particles themselves (as is common in environmental samples) must also be considered as part of the matrix for actual samples (as opposed to SRMs prepared from pure starting materials).

Sharp et al. (2016) focused on determining the effect of analytical substrate using a Cameca IMS-1270 (Section 2.1.5). The primary beam diameter was focused to "smaller" than $10 \mu \mathrm{m}$ for the analysis of individual particles. Although no other information about the beam size was provided in the Sharp et al. (2016) study, the IMS-1270 is not generally considered to be an instrument capable of producing very small primary beams. Considering that the NanoSIMS 50L is capable of producing a primary beam with a sub-micron footprint, a first-order study would be to understand whether the primary ion beam on the NanoSIMS could be focused in such a way so as to avoid the complex matrix effect documented by Sharp et al. (2016) altogether for common particle sizes. If this is possible, it would then be worthwhile to determine the minimum effective particle size to avoid the matrix effect or at least mitigate it by minimizing the amount of substrate sputtered in conjunction with the particle itself.

As discussed in Section 2.1.2, Park et al. (2017) undertook a study to determine the extent to which Gd, Mo, or $\mathrm{Zr}$ impurities interfered with $\mathrm{U}$ isotope particle analysis through the production of molecular isobars on the $U$ isotopic masses of interest. Park et al. (2017) found that although molecular isobar interferences could be mitigated by measurement of $\mathrm{UO}_{2}{ }^{+}$secondary ions (instead of $\mathrm{U}^{+}$), an additional technique (e.g., TOF-SIMS) should be coupled with the dynamic SIMS U isotope analysis in cases where there is the possibility of impurity species being present. Because environmental swipe samples are taken 
in industrial settings, it is not unreasonable to assume that metallic species of concern might become comingled with the particles themselves. Another possibility is that the metallic species of concern might act as nucleation sites for the condensation of aerosolized $\mathrm{UF}_{6}$, in which case the metallic species of concern would actually become present within the particle of interest itself and would thus be unavoidable during SIMS analysis.

The study of Park et al. (2017) was performed using a Cameca $7 f$ instrument. In considering that the NanoSIMS 50L has far superior spatial resolution, one avenue of investigation might be to determine whether it is feasible to include one or serval non- $U$ metallic species in a typical analytical regime that might serve as an impurity monitor (e.g., $\mathrm{Pb}, \mathrm{Mo}, \mathrm{W}, \mathrm{Ti}, \mathrm{Zr}, \mathrm{Ba}, \mathrm{Si}, \mathrm{Mg}$, or $\mathrm{Al}$ ). In cases where there is a preliminary indication that the particle might contain an impurity that could create molecular isobars on the actinide measurement, the NanoSIMS superior spatial resolution could then be used to determine if the impurity is present within the particle or if it is present adjacent to the particle. At that point, it might also be possible to exploit the instrument's superior spatial resolution to perform an analysis that avoids the region being influenced by molecular isobar formation.

\subsubsection{R\&D possibilities related to the detection and measurement of non- $U$ species within materials of interest to nuclear forensics applications}

Nuclear forensic particle analysis has typically focused on the determination of actinide isotopic composition and overall abundance, but there is growing traction within the SIMS community toward incorporating other pieces of information into particle attribution studies. For example, oxygen isotope compositions can provide important geolocation information that could not be gleaned from other information, and trace element characteristics might be able to provide important information about the facility where the material was processed.

As discussed in Section 2.1.2, several studies (Pajo et al. 2001; Tamborini et al. 2002a, 2002b) have demonstrated that the determination of oxygen isotope compositions via SIMS in uranium oxide particles and larger materials is a relatively straightforward endeavor. It is now accepted that oxygen isotope ratios can be acquired for nuclear particles with precision and accuracy comparable to determinations from silicates, which have very well calibrated SRMs. All of the studies (Pajo et al. 2001; Tamborini et al. 2002a, 2002b) presenting oxygen isotope data on materials relevant to nuclear forensics have been collected using the Cameca $6 \mathrm{f}$ and $4 \mathrm{f}$ instruments, but there is no reason to believe that the NanoSIMS would be incapable of performing oxygen isotope ratio measurements on materials in support of a nuclear forensics investigation. This is because oxygen isotope compositions determined via the NanoSIMS are routinely reported in the literature for a variety of other materials.

What has not been demonstrated, however, is the coupling of actinide and oxygen isotope composition for the same particle. This is because oxygen isotope analyses must be performed using a positive primary ion beam (e.g., $\mathrm{Cs}^{+}$), whereas a negative primary ion beam is typically used for the actinide isotope analysis (e.g., $\mathrm{O}^{-}$). The fine spatial resolution of the NanoSIMS makes it the ideal instrument for collecting a data set under $\mathrm{Cs}^{+}$bombardment (e.g., oxygen isotope compositions) followed by a data set under $\mathrm{O}^{-}$bombardment (e.g., actinide isotope compositions). The two data sets can then be reconciled with one another so that any correlations between oxygen and actinide isotopic variations can be visualized.

It is generally well understood that uranium and plutonium oxide particles collected during environmental sampling campaigns can contain impurities that are readily observable using EDS or XRD (e.g., Ranebo et al. 2007; Torok et al. 2004). There is an understanding that these impurities can contribute to elemental and molecular isobaric interferences on the actinide species, but as of yet, there are no SIMS studies that attempt to use these impurities as a means of augmenting the actinide isotope data. In the same way that 
particle morphology has proven to be an important attribute in particle attribution studies, the distribution of the impurity phases within the particles might provide as much information as the total concentration. Because there are no SIMS data yet, an avenue of possible research might be to select a set of environmental particles that have been documented to contain impurities (e.g., via EDS) and then analyze them using the NanoSIMS 50L. The goal would be to understand the detection limits and the extent to which the impurity phase could be resolved in relation to the actinide isotope analysis. Although this might be more effective for larger particles, it might provide a starting point for the inclusion of another piece of information into particle attribution studies.

\subsection{STUDIES IN GEOCHRONOLOGY AND GEOCHEMISTRY}

There are two avenues of possible research in the fields of geochronology and geochemistry that are well suited for the commissioning phase of the instrument. Both will focus on the development of NanoSIMS analytical methods for the mineral zircon, which is widely used as a recorder of age and chemistry in the field of Earth science. The most commonly used geochronometer for zircon is the $\mathrm{U}-\mathrm{Pb}$ isotope system. Typically, $\mathrm{U}-\mathrm{Pb}$ ages represent the crystallization age of the zircon and can be measured using a variety of bulk-dissolution (e.g., TIMS), micro-beam techniques (e.g., LA-ICP-MS or SIMS), or a combination of both. To understand certain geochemical conditions at the time of zircon crystallization, the U-Pb ages are typically combined with data for an isotopic tracer (e.g., oxygen or hafnium).

For zircon U-Pb and oxygen isotope measurement, SIMS is already extensively used. In fact, refinement of the U-Pb measurement capabilities has actually been a driver for some of the advances in the instrumental capabilities offered by the major SIMS manufacturers (e.g., Cameca Inc.). However, there are currently only a small handful of NanoSIMS papers (see Section 2.1.2 of this document for a summary of NanonSIMS zircon $\mathrm{U}-\mathrm{Pb}$ ages) reporting $\mathrm{U}-\mathrm{Pb}$ zircon data and none that report zircon oxygen isotope data. Furthermore, no SIMS instrument has been successfully utilized to measure the hafnium isotope composition of zircon (e.g. to the same level of precision and accuracy as is typical of LA-ICP-MS measurements). Therefore, there is a need to understand the methodological capabilities and limitations of NanoSIMS analysis for $\mathrm{U}-\mathrm{Pb}$ and oxygen isotopes in zircons as well as a need to understand whether hafnium isotope analysis of zircon via SIMS is even possible. It is well understood that the spatial scales of $\mathrm{U}-\mathrm{Pb}$, oxygen, and hafnium isotope variability in zircon are typically much smaller than the resolution afforded by the commonly applied analytical techniques, so methodological development using the NanoSIMS has the capability to substantively advance the field of geochronology and geochemistry.

Methodological research related to zircon $\mathrm{U}-\mathrm{Pb}$, oxygen, and hafnium isotope measurements on the NanoSIMS is ideally suited for completion during the commissioning phase of the instrument because it does not require the purchase of additional equipment for sample processing, the modification of RSS documents, or configuration of the instrument and/or laboratory in a manner that precludes other uses during the period of zircon analysis. This is partly because the primary users are already in possession of a collection of commonly used zircon standards that have been mounted in a manner suitable for NanoSIMS analysis. The zircons are not hazardous or contaminating and can be easily transferred in and out of the instrument without consequence. Therefore, method development using the NanoSIMS should be relatively straightforward. It can also build upon the existing body of literature related to the analyses of these elements in zircon. Furthermore, because of the wide interest in zircon within the geological community as well as the growing number of laboratories with NanoSIMS instruments, there is the expectation that published results of the method development at ORNL would garner widespread attention in the community. 


\subsection{STUDIES IN COSMOCHEMISTRY}

The NanoSIMS has been used routinely in cosmochemistry studies for many years now and is an excellent parallel field that finds a few interesting particles within an abundance of everyday normal particles. Techniques developed for finding these unusual particles can be leveraged for use in the field of nuclear forensics.

Presolar grains formed around other stars, subsequently were swept up into the protoplanetary disk that formed our solar system, and many were preserved in meteorites. They have unusual isotopic compositions that shed light on the chemical evolution of our galaxy and early solar system processes. Presolar grains have a variety of silicate and oxide phases. Measuring oxygen isotopic compositions of some of these phases will aid in our understanding of reaction processes around other stars.

\subsection{STUDIES IN ENERGY RESOURCE SCIENCE}

Coal fly ash (CFA) is currently under consideration as a source of the rare earth elements and yttrium $(\mathrm{REE}+\mathrm{Y})$. CFA is a complex material composed of many different subcomponents, but there is currently very little data on the distribution of the REE $+\mathrm{Y}$ across or within individual CFA particles. Spatially resolved data on the association between the REE $+\mathrm{Y}$ and the environmentally toxic species that also occur within CFA is also lacking. An ORNL Laboratory Directed Research and Development Seed money proposal will be written seeking funding to develop a method for the analysis of the REE $+\mathrm{Y}$ and environmentally toxic species on the ORNL NanoSIMS 50L instrument. This instrument has the capability to precisely and accurately resolve chemical and isotope compositions at the nanometer scale, but it has not yet been applied to CFA. Having the ability to document the distribution of REE + Y, and their co-location with environmental toxins, within CFA will help refine REE + Y extraction technologies and guide future research on the optimization of CFA as a REE + Y resource. The results of this research will be published in scholarly journals. Figure 2 provides a graphical representation of the approach to developing a NanoSIMS method for CFA REE + Y analysis; a copy of the Laboratory Directed Research and Development proposal is available upon request.

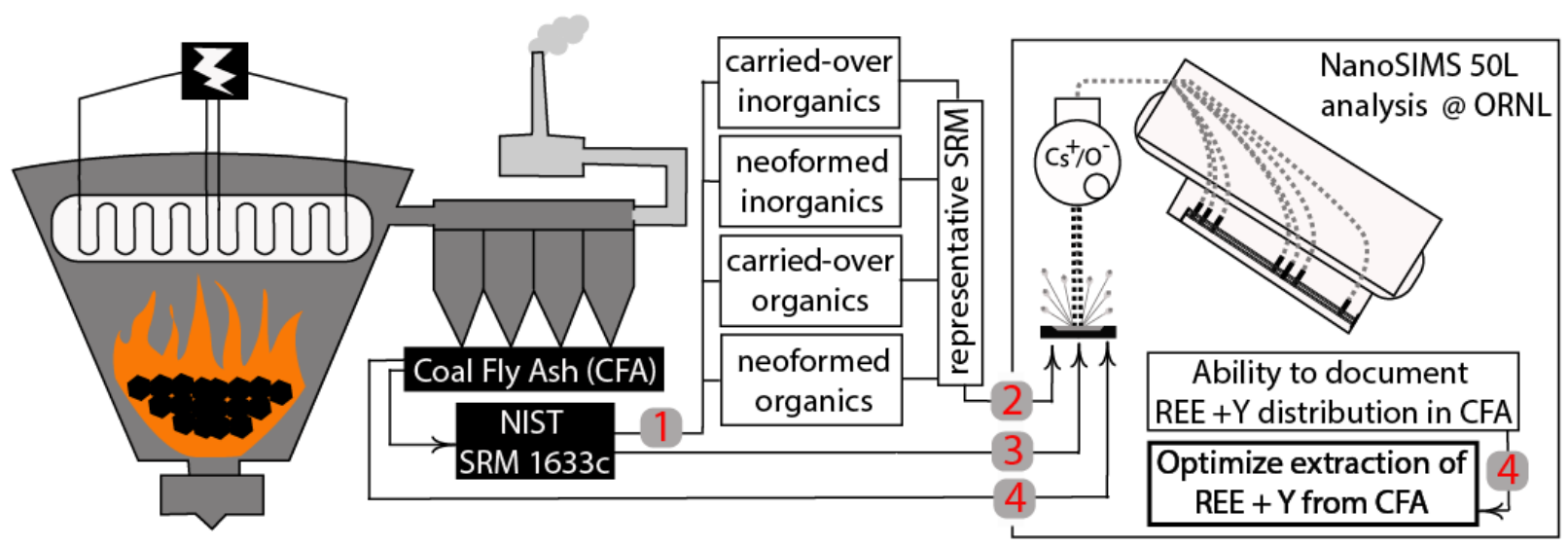

Figure 2. Schematic illustrating the approach to developing a method for the NanoSIMS analysis of REE + Y and environmental toxins in CFA. The numbers correspond to the four objectives described in the proposal's test. Objectives 1 and 2 represent a series of analytical methods that will be developed for a suite of SRMs representing the subcomponents of SRM 1633c (the National Institute of Standards and Technology [NIST] CFA trace element standard). In objective three, these methods will then be applied to document the distribution of the REE + Y and environmental toxins within SRM 1633c. In objective four, this knowledge will be used to guide further investigation into the optimization of CFA REE + Y extraction technologies. 


\subsection{STUDIES IN BIOLOGY}

Based on a discussion with group and task leaders in the ORNL Biosciences Division that took place on April 12, 2017, there will likely be a project that uses the NanoSIMS to examine ${ }^{13} \mathrm{C},{ }^{15} \mathrm{~N},{ }^{2} \mathrm{H}$ labeled plant or microbial material, or a combination of materials. The aim will be to apply the NanoSIMS technique to ongoing research focused on developing a better understanding of nutrient cycling at the sub-micron scale. Based on our explanation of NanoSIMS capabilities, researchers in the Biosciences Division are now devising possible incubation experiments whose outputs could be analyzed on the NanoSIMS instrument. Our goal is to meet before the end of fiscal year 2018 to discuss sample preparation requirements and method development specific to the project possibilities.

Table 3. List of SRMs possibly needed to demonstrate capability to the academic community. Some of these overlap with the SRMs that will be used to develop sponsor-specific research and development activities for stable isotopes.

\begin{tabular}{|c|c|c|c|c|c|}
\hline Name & Material & $\begin{array}{c}\text { Certified } \\
\text { Component }\end{array}$ & Source & Amount & Price \\
\hline \multicolumn{6}{|c|}{ Stable isotope standards: } \\
\hline NBS-28 & Quartz sand & $\square^{18} \mathrm{O} \& \square^{30} \mathrm{Si}$ & IAEA & $0.5 \mathrm{~g}$ & $€ 150$ \\
\hline USGS-24 & Graphite shards & $\square{ }^{13} \mathrm{C}$ & IAEA & & $€ 150$ \\
\hline V-PDB & Vienna Pee Dee Belemnite & $\square{ }^{13} \mathrm{C}$ & & & \\
\hline SRM-1577b & Bovine liver & $\square{ }^{13} \mathrm{C} \& \square{ }^{15} \mathrm{~N}$ & NIST & $20 \mathrm{~g}$ & $\$ 680$ \\
\hline San Carlos Olivine & Olivine & $\square{ }^{18} \mathrm{O} \square^{57} \mathrm{Fe}$ & & & \\
\hline IRMM 014 & & $\square^{56} \mathrm{Fe} \square^{57} \mathrm{Fe}$ & & & \\
\hline IAEA-N-1 & $\begin{array}{l}\text { Coarse grained ammonium } \\
\text { sulfate }\end{array}$ & $\square{ }^{15} \mathrm{~N}$ & IAEA & $0.5 \mathrm{~g}$ & $€ 150$ \\
\hline USGS-32 & Potassium nitrate granules & $\square{ }^{15} \mathrm{~N} \& \square{ }^{18} \mathrm{O}$ & IAEA & $0.5 \mathrm{~g}$ & $€ 150$ \\
\hline IAEA-603 & Calcite granules & $\square{ }^{18} \mathrm{O} \& \square{ }^{13} \mathrm{C}$ & IAEA & $0.5 \mathrm{~g}$ & $€ 150$ \\
\hline Burma spinel & $\left(\mathrm{MgAl}_{2} \mathrm{O}_{4}\right)$ & $\square{ }^{18} \mathrm{O}$ & & & \\
\hline Miakejima Anorthite & $\left(\mathrm{CaAl}_{2} \mathrm{Si}_{2} \mathrm{O}_{8}\right)$ & $\square{ }^{18} \mathrm{O}$ & & & \\
\hline IAEA-S-1 & Silver sulfide & $\square{ }^{34} \mathrm{~S}$ & IAEA & $0.5 \mathrm{~g}$ & $€ 180$ \\
\hline IAEA-SO-5 & Barium sulfate & $\square{ }^{34} \mathrm{~S}$ & IAEA & $0.5 \mathrm{~g}$ & $€ 150$ \\
\hline VCDT & Vienna Canyon Diablo Troilite & 32333436 & & & \\
\hline IAEA-B-6 & Obsidian shards & $\square^{11} \mathrm{~B}$ & IAEA & $30 \mathrm{~g}$ & $€ 60$ \\
\hline ISL-354 & Sodium chloride granules & $\square{ }^{37} \mathrm{Cl} \&{ }^{37} \mathrm{Cl} /{ }^{35} \mathrm{Cl}$ & IAEA & $2.0 \mathrm{~g}$ & $€ 150$ \\
\hline Spodumene & Mineral: $\mathrm{LiAlSi}_{2} \mathrm{O}_{6}$ & ${ }^{6} \mathrm{Li} /{ }^{7} \mathrm{Li}$ & & & \\
\hline LSVEC & Lithium carbonate granules & $\square{ }^{13} \mathrm{C}, \square^{18} \mathrm{O}, \&^{6} \mathrm{Li} /{ }^{7} \mathrm{Li}$ & IAEA & $0.5 \mathrm{~g}$ & Out \\
\hline \multicolumn{6}{|c|}{ Energy critical materials: } \\
\hline IAEA-RGU1 & Uranium ore in silica powder & ${ }^{232} \mathrm{Th},{ }^{235+238} \mathrm{U},{ }^{40} \mathrm{~K}$ & IAEA & $500 \mathrm{~g}$ & $€ 60$ \\
\hline SRM 1632d & Bituminous coal & Trace elements & NIST & $50 \mathrm{~g}$ & $\$ 732$ \\
\hline SRM $1633 c$ & Coal fly ash & Trace elements & NIST & $75 \mathrm{~g}$ & $\$ 698$ \\
\hline \multicolumn{6}{|c|}{ Trace element analysis: } \\
\hline SRM 611 & Synthetic doped glass & Trace elements & NIST & Wafers & $\$ 545$ \\
\hline REEM25-15 & $\begin{array}{l}\text { REE (native metals \& } \\
\text { fluorides) }\end{array}$ & Lanthanides & Astimex & Mount & $\$ 1,100$ \\
\hline
\end{tabular}


Table 3. List of SRMs possibly needed to demonstrate capability to the academic community (continued).

\begin{tabular}{|c|c|c|c|c|c|}
\hline Name & Material & $\begin{array}{c}\text { Certified } \\
\text { Component }\end{array}$ & Source & Amount & Price \\
\hline \multicolumn{6}{|c|}{ Metals analysis: } \\
\hline SRM $1577 \mathrm{c}$ & Bovine liver & Various metals & NIST & $20 \mathrm{~g}$ & $\$ 680$ \\
\hline \multicolumn{6}{|c|}{ Standards currently in lab: } \\
\hline Zircon & Variety of zircon standards & $\mathrm{U}-\mathrm{Pb}, \mathrm{Hf}, \mathrm{Ti}$ & In house & Crystals & $\mathrm{N} / \mathrm{A}$ \\
\hline Apatite & Large crystal of Durango std. & Trace elements, U-Th & In house & Crystal & $\mathrm{N} / \mathrm{A}$ \\
\hline BCRC-2 & Powdered fused basalt & Trace/major elements & USGS & Powder & N/A \\
\hline
\end{tabular}

\section{COMMISSIONING TIMELINE AND CONCLUDING REMARKS}

The goal of the commissioning phase is to develop a world-class analytical facility centered around the capabilities of the NanoSIMS 50L. From its inception, the ORNL NanoSIMS facility has never been intended as a user facility or a research laboratory that is funded primarily through its pursuit of purely academic questions. Therefore, metrics of success (and the path towards attaining these metrics) are somewhat different from those that would define the successful commissioning of an academic laboratory (e.g., a certain number of papers published) or a user facility (e.g., a certain number of external users). Instead, commissioning will have been successful once the facility has shown its staff, the academic community, and most importantly its sponsors that it can produce high-quality data relevant to specific research questions. Nonetheless, a loose timeline for commissioning was established once funding for the instrument was secured (Figure 1). However, as of November 2017, unforeseen technical difficulties related to the manufacture and installation of the instrument have led to a slip in the originally planned timeline of approximately 6 months (Figure 1). Despite these setbacks, the aim is to begin the solicitation of funding from various agencies during FY 2018. Therefore, some of the more academically oriented aspects of the commissioning plan may need to be put on hold to establish the methodologies that will be used to garner funding for the instrument.

\section{REFERENCES}

Benninghoven, A, Rudenaur, FG, Wemer, HW. 1987. Secondary ion mass spectrometry: Basic concepts, instrumental aspects, applications and trends. New York: Wiley.

Betti, M, Tamborini, G, Koch, L. 1999. Use of Secondary Ion Mass Spectrometry in Nuclear Forensics Analysis for the Characterization of Plutonium and Highly Enriched Uranium Particles. Analytical Chemistry 71: 2616-2622.

Bowen, J, Glover, S, Spitz, H. 2013. Morphology of actinide-rich particles released from the BOMARC accident and collected rom soil post remediation. Journal of Radiological and Nuclear Chemistry 296: 853-857.

Cameca, 2016, NanoSIMS 50L: Introduction to the instrumentation-Secondary ion mass spectrometer for trace element and isotope analysis at sub-micron resolution. Ametek ${ }^{\circledR}$ Materials Analysis Division, Available: www.cameca.com/literature/product-brochures.aspx (Accessed March 21, 2017).

Clement, SWJ, Compston, W, Newstead G. 1977. Design of a large, high resolution ion microprobe. International Secondary Ion Mass Spectrometry Conference, Springer (Muenster). 
Danesi, PR, Markowicz, A, Chinea-Cano, E, Burkart, W, Salbu, B, Donohue, D, Ruedeneaur, F, Hedberg, M, Vogt, S, Zahadrnik, P, Ciurapinski, A. 2003. Depleted uranium particles in selected Kosovo samples. Journal of Environmental Radioactivity 64: 143-154.

Donohue, D, Ciurapinski, A, Cliff, J, Rudenaur, F, Kuno, T, Poths, J. 2008. Microscopic studies of spherical particles for nuclear safeguards. Applied Surface Science 255: 2561-2568.

Donohue, DL, Zeisler, R. 1993. Analytical Chemistry in the Aftermath of the Gulf War. Analytical Chemistry 65: 359A-368A.

Erdmann, N, Betti M, Stezer, O, Tamborini, G, Kratz, JV, Trautmann, N, VanGeel, J. 2000. Production of monodisperse uranium oxide particles and their characterization by scanning electron microscopy and secondary ion mass spectrometry. Spectrochimica Acta Part B: Atomic Spectroscopy 55: 1565-1575.

Esaka, F, Watanabe, K, Fukuyama, H, Onodera, T, Esaka, K, Magara, M, Sakurai, S, Usuda, S. 2004a. Efficient isotope ratio analysis of uranium particles in swipe samples by total-reflection X-ray fluorescence spectrometry and secondary ion mass spectrometry. Journal of Nuclear Science and Technology 41: 1027-1032.

Esaka, F, Watanabe, K, Magara, M, Usuda, S. 2004b. Applications of secondary ion mass spectrometry to the measurement of lead isotope ratio in individual particles. Instrumentation Science and Technology 32: $103-114$.

Esaka, F, Magara, M. 2014. Secondary ion mass spectrometry combined with alpha track detection for isotope abundance ratio analysis of individual uranium-bearing particles. Talanta 120: 349-354.

Esaka, F, Esaka, KT, Lee, CG, Magara, M, Sakurai, S, Usuda, S, Watanabe, K. 2007. Particle isolation for analysis of uranium minor isotopes in individual particles by secondary ion mass spectrometry. Talanta 71: 1011-1015.

Esaka, F, Watanabe, K, Onodera, T, Lee, CG, Magara, M, Sakurai, S, Usuda, S. 2008. Dependence of the precision of uranium isotope ratio on particle diameter in individual particle analysis by SIMS. Applied Surface Science 255: 1512-1515.

Esaka, F, Magara, M, Lee, CG, Sakurai, S, Usuda, S, Shinodera, N. 2009. Comparison of ICP-MS and SIMS techniques for determining uranium isotope ratios in individual particles. Talanta 78: 290-294.

Esaka, F, Magara, M, Suzuki, D, Miyamoto, Y, Lee, CG, Kimura, T. 2011. Feasibility study of isotope ratio analysis of individual uranium-plutonium mixed oxide particles with SIMS and ICP-MS. Mass Spectrometry Letters 2: 80-83.

Esaka, F, Lee, CG, Magama, M, Kimura, T. 2012. Fission track-secondary ion mass spectrometry as a tool for detecting the isotopic signature of individual uranium containing particles. Analytica Chimica Acta 721: 122-128.

Faure, AL, Dalger, T. 2017. Age dating of individual micrometer-sized uranium particles by secondary ion mass spectrometry: An additional fingerprint for nuclear safeguards purposes. Analytical Chemistry 89: 6663-6669. 
Faure, AL, Rodriguez, C, Marie, O, Aupiais, J, Pointurier, F. 2014. Detection of traces of fluorine in micrometer sized uranium bearing particles using SIMS. Journal of Analytical Atomic Spectrometry 29: $145-151$.

Hedberg, PML, Peres, P, Cliff, JB, Rabermananjar, F, Littmann, S, Thiele, H, Vincent, C, Albert, N. 2011. Improved particle location and isotopic screening measurements of sub-micron sized particles by secondary ion mass spectrometry. Journal of Analytical Atomic Spectrometry 26: 406-413.

Horreard, F. 2017. N50-Scientific-Articles-Compilation. Database published by Cameca. Available: http://www.cameca.com/products/sims/nanosims.

Hoppe, P, Cohen, S, Meibom, A. 2013. NanoSIMS: Technical aspects and applications in cosmochemistry and biological geochemistry. Geostandards and Geoanalytical Research 37: 111-154.

Ireland, TR. 1995. Ion microprobe mass spectrometry: Techniques and applications in cosmochemistry, geochemistry, and geochronology. Advances in Analytical Geochemistry 2: 1-118.

Kips, R, Kristo, MJ, Crowhurst, J, Stefaniak, E, Aregbe, Y, Hutcheon, ID 2010. IAEA Symposium on International Safeguards; Report no. LLNL-PRES-461234, Lawrence Livermore National Laboratory, Livermore, CA.

Kips, R, Leenaers, A, Tamborini, G, Betti, M, Berge, SVd, Wellum, R, Taylor, P. 2007. Characterization of uranium particles produced by hydrolosis of UF6 using SEM and SIMS. Microscopy and Microanalysis 13: 156-164.

Kips, R, Pidduck, AJ, Houlton, MR, Leenaers, A, Mace, JD, Marie, O, Pointurier, F, Stefaniak, EA, Taylor, PDP, bergeh, SVd, Espen, PV, VanGrieken, R, Wellum, R. 2009. Determination of fluorine in uranium oxyfluoride particlces as an indicator of particle age. Spectrochimica Acta Part B 64: 199-207.

Kips, RS, Kristo, MJ. 2009. Investigation of chemical changes in uranium oxyfluoride particles using secondary ion mass spectrometry. Journal of Radioanalytical Nuclear Chemistry 282: 1031-1035.

Lepareur, M. 1980, Le mico-analyseur ionique de second generation Cameca, model 3F. Revue Technique Thomson-CSF 12: 225-265.

Letho, S, Lipponen, M, Zillicus, R. 2003. Development of Methods for Isotopic Analysis of Uranium Containing Particles. Report no. STUK-YTO-TR 200, STUK, Helsinki, Finland.

Morgan, AE. 1980. An alternative to the relative sensitivity factor approach to quantitative SIMS analysis. Surface and Interface Analysis 2: 123-133.

Pajo, L, Tamborini, G, Rasmussen, G, Mayer, K, Koch, L. 2001. A novel isotope analysis of oxygen in uranium oxides: comparison of secondary ion mass spectrometry, glow discharge mass spectrometry and thermal ionization mass spectrometry. Spectrochimica Acta Part B: Atomic Spectroscopy 56: 541-549.

Park, J, Kim, TH, Lee, CH, Lee, J, Lim, SH, Han, SH, Son, K. 2017. Combinatory use of time-of-flight secondary ion mass spectrometry (SIMS) and sector-field SIMS for estimating elemental and isotopic compositions of nuclear forensic samples. Journal of Radioanalytical Nuclear Chemistry 311: 15351544. 
Peres, P, Hedberg, PML, Walton, S, Montgomery, N, Cliff, JB, Rabemananjara, R, Schumacher, M. 2012. Nuclear safeguards applications using LG-SIMS with automated screening capabilities. Surface Interface Analysis 45: 561-565.

Ranebo, Y, Niagolova, N, Erdmann, N, Eriksson, M, Tamborini, G, Betti, M. 2010. Production and characterization of monodisperse plutonium, uranium, and mixed uranium-plutonium particles for nuclear safeguards applications. Analytical Chemistry 82: 4055-4062.

Ranebo, Y, Eriksson, M, Tamborini, G, Niagolova, N, Bildstein, O, Betti, M. 2007. The use of SIMS and SEM for the characterization of individual particles with a matrix originating from a nuclear weapon. Microscopy and Microanalysis 13: 179-190.

Sabionia, ACS, Ferraz, WB, Millot, F. 1998. First study of uranium self-diffusion in $\mathrm{UO}_{2}$ by SIMS. Journal of Nuclear Materials 257: 180-184

Sharp, N, Fassett, JD, Simons, DS. 2016. Uranium ion yields from monodisperse uranium oxide particles. Journal of Vacuum Science and Technology 34: 03H115-1 to 03H115-6.

Shimizu, N, Hart, SR. 1982. Applications of the ion microprobe to geochemistry and cosmochemistry. Annual Reviews in Earth and Planetary Sciences 10: 483-526.

Simons, DS, Fassett, JD. 2017. Measurement of uranium-236 in particles by secondary ion mass spectrometry. Journal of Analytical Atomic Spectrometry 32: 393-401.

Stanley, FE, Stalcup, AM, Spitz, HB. 2013. A brief introduction to analytical methods in nuclear forensics. Journal of Radioanalytical and Nuclear Chemistry 295: 1385-1393.

Stoffels, JJ, Briant, JK, Simons, DS. 1994. A particulate isotopic standard of uranium and plutonium in an aluminosilicate matrix. Journal of the American Society for Mass Spectrometry 5: 852-858.

Tamborini, G. 2004. SIMS analysis of uranium and actinides in microparticles of different origin. Microchimica Acta 145: 237-242.

Tamborini, G, Betti, M. 2000. Characterization of radioactive particles by SIMS. Microchimica Acta 132: 411-417.

Tamborini, G, Betti, M, Forcina, V, Hiernaut, T, Giovannone, B, Koch, L. 1998. Application of secondary ion mass spectrometry to the identification of single particles of uranium and their isotopic measurement. Spectrochimica Acta Part B 53: 1289-1302.

Tamborini, G, Phinney, D, Bildstein, O, Betti, M. 2002a. Oxygen isotopic measurements by secondary ion mass spectrometry in uranium oxide microparticles: A nuclear forensics diagnostic. Analytical Chemistry 74: 6098-6101.

Tamborini, G, Wallenius, M, Bildstein, O, Pajo, L, Betti, M. 2002b. Development of a SIMS method for isotopic measurements in nuclear forensic applications. Microchimca Acta 139: 185-188.

Tarolli, JG, Naes, BE, Garcia, BJ, Fischer, AE, Willingham, D. 2016. High resolution isotopic analysis of U-bearing particles via fusion of SIMS and EDS images. Journal of Analytical Atomic Spectrometry 1: 1472-1479. 
Torok, S, Osan, J, Vincze, L, Kurunzi, S, Tamborini, G, Betti, M. 2004. Characterization and speciation of depleted uranium in individual soil particles using microanalytical methods. Spectrochimica Acta Part B: Atomic Spectroscopy 59: 689-699.

Wallenius, M, Tamborini, G, Koch, L. 2001. The "age" of plutonium particles. Radiochimica Acta 89: $55-58$.

Walther, C. 2011. Actinide nanoparticle characterization by mass spectrometry. Actinide Nanoparticle Research. doi: 10.1007/978-3-642-11432-8_5.

Wellons, MS, DeVore, MA, Rogers, RM, Hewitt, JT, Williamson, TL Tenner, TJ, Darroudi, T. 2017. Practical utilization of uranium-containing particular test samples for SEM/EDS and SIMS automated particle analysis method validation. Microscopy and Microanalysis 23, 514-515.

Willingham, D, Naes, BE, Heasler, PG, Zimmer, MM, Barrett, CA, Addleman, S. 2016. Image segmentation for uranium isotopic analysis by SIMS: Combined adaptive thresholding and marker controlled watershed approach. Journal of Vacuum Science and Technology 34, 03H106-1 to 03H106-9.

Wilson, RG, Novak, W. 1991. Systematics of secondary-ion-mass spectrometry relative sensitivity factors versus electron affinity and ionization potential for a variety of matrices determined from implanted standards of more than 70 elements. Journal of Applied Physics 69: 466-474. 

APPENDIX A. SUMMARY OF ACTINIDE PARTICLE ANALYSIS BY SIMS 



\begin{tabular}{|c|c|c|c|c|c|c|}
\hline $\begin{array}{l}\text { Authors and } \\
\text { affiliation }{ }^{1,2}\end{array}$ & Instrument and lab & Aim of study & SIMS particle mounting technique & Outcome & $\begin{array}{c}\text { Primary beam } \\
\text { information }\end{array}$ & $\begin{array}{c}\text { SIMS masses } \\
\text { analyzed }\end{array}$ \\
\hline \multicolumn{7}{|c|}{ Unknown particles in soil } \\
\hline $\begin{array}{l}\text { Danesi et al. } \\
2003 \\
\text { (IAEA) }\end{array}$ & $\begin{array}{l}\text { IMS-4f @ Unspec. } \\
\text { Loc. }\end{array}$ & $\begin{array}{l}\text { Determine suitability of } \\
\text { XRF, SIMS, \& SEM-EDS } \\
\text { for analysis of depleted U } \\
\text { particles in soil }\end{array}$ & $\begin{array}{l}\text { Soil matrix containing depleted } \mathrm{U} \\
\text { particles suspended in heptane and } \\
\text { then pipetted onto heated pyrolytic } \\
\text { graphic planchet ( } 2.5 \mathrm{~cm} \text { diameter). }\end{array}$ & $\begin{array}{l}{ }^{235} \mathrm{U}^{238} \mathrm{U} \text { by SIMS was } \\
\text { successful. }\end{array}$ & $\begin{array}{l}\mathrm{O}_{2}^{+} \\
\text {Rastering used }\end{array}$ & $\begin{array}{l}{ }^{235} \mathrm{U} \&{ }^{238} \mathrm{U} \text { (blank } \\
\text { measured at }{ }^{233} \mathrm{U} \text { and } \\
{ }^{234} \mathrm{U} \text { ) }\end{array}$ \\
\hline $\begin{array}{l}\text { Tamborini \& } \\
\text { Betti } 2000 \\
\text { (ITE) }\end{array}$ & $\begin{array}{l}\text { IMS-6f @ Unspec. } \\
\text { Loc. }\end{array}$ & $\begin{array}{l}\text { Analyze U \& Pu isotope } \\
\text { composition of particles } \\
\text { in soil from Chernobyl } \\
\text { area }\end{array}$ & $\begin{array}{l}\text { U particles from swipes \& soils were } \\
\text { transferred onto special adhesive } \\
\text { supports (Leit-Tabs) that were } \\
\text { mounted on metallic discs and } \\
\text { carbon coated. Pu particles were } \\
\text { embedded in foil of indium metal. } \\
\text { SIMS blanks were tested on the } \\
\text { carbon coated adhesive mount and } \\
\text { the indium foil. }\end{array}$ & $\begin{array}{l}\text { No discussion of effect of } \\
\text { mounting medium on U } \\
\text { and Pu isotope } \\
\text { compositions. SIMS } \\
\text { results were consistent } \\
\text { with expected values. }\end{array}$ & $\begin{array}{l}0.5-2 \mathrm{nA} \mathrm{O}_{2}^{+} \\
0.5-2 \mu \mathrm{m} \text { lateral } \\
\text { res. }\end{array}$ & \begin{tabular}{|l}
${ }^{234} \mathrm{U},{ }^{235} \mathrm{U},{ }^{238} \mathrm{U}$ \\
${ }^{239} \mathrm{Pu},{ }^{240} \mathrm{Pu}$ \\
(elemental and oxide)
\end{tabular} \\
\hline $\begin{array}{l}\text { Torok et al. } \\
2004 \text { (KFKI) }\end{array}$ & IMS-6f @ ITE & $\begin{array}{l}\text { Use SIMS to identify } \\
\text { origin of depleted U } \\
\text { particles in soil }\end{array}$ & $\begin{array}{l}\text { Soil particles suspended in n-hexane } \\
\text { containing rubber cement followed } \\
\text { by ultrasonic vibration and mounting } \\
\text { on high purity carbon planchette by } \\
\text { dispersion. }\end{array}$ & $\begin{array}{l}\text { U isotope composition of } \\
\text { individual particles was } \\
\text { determined by SIMS. }\end{array}$ & $\begin{array}{l}1-2 \mathrm{nA} \mathrm{O}_{2}^{+} \\
3-5 \mu \mathrm{m} \text { lateral } \\
\text { res. }\end{array}$ & $\begin{array}{l}{ }^{234} \mathrm{U},{ }^{235} \mathrm{U},{ }^{236} \mathrm{U},{ }^{238} \mathrm{U} \\
\text { (elemental and oxide) }\end{array}$ \\
\hline \multicolumn{7}{|c|}{ Unknown particles collected on surface swipes } \\
\hline $\begin{array}{l}\text { Donohue et al. } \\
2008 \text { (IAEA) }\end{array}$ & $\begin{array}{l}\text { IMS-4f @ Unspec. } \\
\text { Loc. }\end{array}$ & $\begin{array}{l}\text { Combine multiple } \\
\text { analysis techniques to } \\
\text { characterize nuclear } \\
\text { particles }\end{array}$ & \begin{tabular}{|l|} 
Particles removed from swipe \\
samples by adhesive disk for \\
analysis via SEM \& EDX. \\
Subpopulation of particles removed \\
from adhesive disk and mounted on \\
pyrolytic graphite planchet for SIMS \\
analysis.
\end{tabular} & $\begin{array}{l}\text { Unclear whether adhesive } \\
\text { disk effected SIMS U- } \\
\text { isotope determination. }\end{array}$ & $100-500 \mathrm{nA} \mathrm{O}_{2}^{+}$ & \begin{tabular}{|l}
${ }^{232} \mathrm{Th},{ }^{238} \mathrm{U},{ }^{23} \mathrm{Na}$, \\
${ }^{28} \mathrm{Si},{ }^{48} \mathrm{Ti},{ }^{208} \mathrm{~Pb}$
\end{tabular} \\
\hline $\begin{array}{l}\text { Esaka et al. } \\
\text { 2004a } \\
\text { (JAERI) }\end{array}$ & $\begin{array}{l}\text { IMS-6f @ Unspec. } \\
\text { Loc. }\end{array}$ & $\begin{array}{l}\text { Test effect of new particle } \\
\text { recovery method on U } \\
\text { isotope determination by } \\
\text { SIMS }\end{array}$ & $\begin{array}{l}\text { Diluted Apiezon grease applied to } \\
\text { silicon wafer used as carrier for } \\
\text { mounting particles aspirated directly } \\
\text { from swipe sample. }\end{array}$ & $\begin{array}{l}\text { SIMS U-isotope } \\
\text { composition was faithful } \\
\text { to standard; Grease } \\
\text { reduced background } \\
\text { contribution from SI } \\
\text { clusters. } \\
\end{array}$ & $\begin{array}{l}30 \mathrm{nA} \mathrm{O}_{2}^{+} \\
<10 \mu \mathrm{m} \mathrm{lateral}^{+} \\
\text {res. }\end{array}$ & $\begin{array}{l}{ }^{236} \mathrm{U},{ }^{237} \mathrm{X},{ }^{235} \mathrm{U},{ }^{238} \mathrm{U}, \\
{ }^{239} \mathrm{Pu}\end{array}$ \\
\hline
\end{tabular}




\begin{tabular}{|c|c|c|c|c|c|c|}
\hline $\begin{array}{c}\text { Authors and } \\
\text { affiliation }{ }^{1,2} \\
\end{array}$ & Instrument and lab & Aim of study & SIMS particle mounting technique & Outcome & $\begin{array}{c}\begin{array}{c}\text { Primary beam } \\
\text { information }\end{array} \\
\end{array}$ & $\begin{array}{c}\text { SIMS masses } \\
\text { analyzed }\end{array}$ \\
\hline $\begin{array}{l}\text { Esaka \& } \\
\text { Magara } 2014 \\
\text { (JAERI) }\end{array}$ & $\begin{array}{l}\text { IMS-6f @ Unspec. } \\
\text { Loc. }\end{array}$ & $\begin{array}{l}\text { Use alpha-track detection } \\
\text { to identify particles of } \\
\text { interest for SIMS analysis }\end{array}$ & $\begin{array}{l}\text { Particles transferred onto silicon } \\
\text { wafers via micromanipulation } \\
\text { followed by coating with } \\
\text { polycarbonate solution and co- } \\
\text { location with alpha track recorder. } \\
\text { Coated particles of interest then } \\
\text { transferred onto glassy carbon } \\
\text { planchette followed by plasma } \\
\text { ashing before SIMS analysis. } \\
\end{array}$ & $\begin{array}{l}\text { SIMS U-isotope } \\
\text { composition was faithful } \\
\text { to standard value. }\end{array}$ & 6-18 $\mathrm{nA} \mathrm{O}_{2}^{+}$ & $\begin{array}{l}{ }^{234} \mathrm{U},{ }^{235} \mathrm{U},{ }^{236} \mathrm{U},{ }^{238} \mathrm{U}, \\
{ }^{238} \mathrm{U}^{1} \mathrm{H}\end{array}$ \\
\hline $\begin{array}{l}\text { Esaka et al. } \\
2012 \\
\text { (JAERI) }\end{array}$ & $\begin{array}{l}\text { IMS-6f @ Unspec. } \\
\text { Loc. }\end{array}$ & $\begin{array}{l}\text { Use fission-track } \\
\text { detection to identify } \\
\text { particles of interest for } \\
\text { SIMS analysis } \\
\end{array}$ & $\begin{array}{l}\text { Particles in polycarbonate solution } \\
\text { transferred and fixed onto glassy } \\
\text { carbon planchette followed by } \\
\text { analysis via SIMS. }\end{array}$ & $\begin{array}{l}\text { Polycarbonate film effects } \\
\text { U-isotope determination } \\
\text { by SIMS. Plasma ashing } \\
\text { overcomes this problem. } \\
\end{array}$ & $\begin{array}{l}4-15 \mathrm{nA} \mathrm{O}_{2}^{+} \\
<10 \mu \mathrm{m} \text { lateral } \\
\text { res. }\end{array}$ & $\begin{array}{l}{ }^{234} \mathrm{U},{ }^{235} \mathrm{U},{ }^{236} \mathrm{U},{ }^{238} \mathrm{U}, \\
{ }^{238} \mathrm{U}^{1} \mathrm{H}\end{array}$ \\
\hline $\begin{array}{l}\text { Faure et al. } \\
2014 \text { (CEA) }\end{array}$ & $\begin{array}{l}\text { IMS-7f @ Unspec. } \\
\text { Loc. }\end{array}$ & $\begin{array}{l}\text { Determine F content of } \\
\text { U-bearing particles using } \\
\text { SIMS and investigate heat } \\
\text { treatment of mounts }\end{array}$ & $\begin{array}{l}\text { Transfer of particles from swipe onto } \\
\text { carbon planchette coated with } \\
\text { polyisobutylene in nonane via } \\
\text { vacuum impaction. Particles also } \\
\text { deposited in ethanol droplets onto } \\
\text { carbon planchettes. }\end{array}$ & $\begin{array}{l}\text { Heat treatment of particle } \\
\text { mounts (e.g., to remove } \\
\text { organics) induces F loss. } \\
\text { Organic fixing agent does } \\
\text { not appear to effect F } \\
\text { content or U isotope } \\
\text { values. } \\
\end{array}$ & $\begin{array}{l}150 \mathrm{nA} \mathrm{O}_{2}^{+} \text {with } \\
500 \times 500 \mu \mathrm{m} \\
\text { raster } \\
\text { Or } 250 \mathrm{pA} \mathrm{O}_{2}^{+} \\
\text {with no raster }\end{array}$ & $\begin{array}{l}{ }^{150} \mathrm{nA}:{ }^{233} \mathrm{U},{ }^{238} \mathrm{U},{ }^{238} \mathrm{UF} \\
\\
250 \mathrm{pA}:{ }^{234} \mathrm{U},{ }^{235} \mathrm{U} \\
{ }^{236} \mathrm{U},{ }^{238} \mathrm{U},{ }^{238} \mathrm{UH} \\
{ }^{238} \mathrm{UF}\end{array}$ \\
\hline $\begin{array}{l}\text { Hedberg et al. } \\
2011 \text { (ITE) }\end{array}$ & $\begin{array}{l}\text { IMS-1280@ UWA } \\
\text { \&IMS 4FE6-PC @ } \\
\text { ITE }\end{array}$ & $\begin{array}{l}\text { Develop automated } \\
\text { particle recognition and } \\
\text { analysis } \\
\text { protocols/software }\end{array}$ & \begin{tabular}{|l|} 
Particulates from swipe samples \\
transferred onto pyrolitical graphite \\
planchettes via vacuum impaction \\
and particulates suspended in \\
isopropanol pipetted onto pyrolitical \\
graphic planchets.
\end{tabular} & $\begin{array}{l}\text { Automated Particle } \\
\text { Management software was } \\
\text { developed. }\end{array}$ & \begin{tabular}{|l|} 
4FE6-pC: $1-5 \mathrm{nA}$ \\
$\mathrm{O}_{2}^{+}$ \\
$(100-200 \mathrm{nA}$ \\
screening $)$ \\
$1280: 1-5 \mathrm{nA} \mathrm{O}_{2}^{-}$ \\
$(80-130 \mathrm{nA}$ \\
screening $)$ \\
\end{tabular} & $\begin{array}{l}{ }^{234} \mathrm{U},{ }^{235} \mathrm{U},{ }^{238} \mathrm{U}^{1} \mathrm{H} \text { for } \\
\text { both instruments. } \\
{ }^{236} \mathrm{U} \text { on } 1280 \text { only }\end{array}$ \\
\hline \multicolumn{7}{|c|}{ Particles produced from known compositions expressly for protocol development } \\
\hline $\begin{array}{l}\text { Betti et al. } 1999 \\
\text { (ITE) }\end{array}$ & $\begin{array}{l}\text { IMS-6f @ Unspec. } \\
\text { Loc. }\end{array}$ & $\begin{array}{l}\text { Compare SIMS and TIMS } \\
\text { for nuclear forensics } \\
\text { particle analysis }\end{array}$ & $\begin{array}{l}\text { Particles of interest were applied to } \\
\text { Leit-Tabs mounted on aluminum } \\
\text { discs. }\end{array}$ & $\begin{array}{l}\text { SIMS is comparable to } \\
\text { TIMS for overall } \\
\text { effectiveness; trace } \\
\text { elements can also be } \\
\text { measured. }\end{array}$ & \begin{tabular}{|l|}
$100-200 \mathrm{nA} \mathrm{O}_{2}^{+}$ \\
for $\mathrm{U}^{+}$ \\
$1-2 \mathrm{nA} \mathrm{O}_{2}^{+}$for $\mathrm{Pu}$ \\
$0.5-2 \mu \mathrm{m}$ lateral \\
res. \\
Rastering used \\
\end{tabular} & $\begin{array}{l}{ }^{239} \mathrm{Pu},{ }^{240} \mathrm{Pu},{ }^{234} \mathrm{U} \\
{ }^{235} \mathrm{U},{ }^{238} \mathrm{U} \text { (elemental } \\
\text { \& oxide) }\end{array}$ \\
\hline $\begin{array}{l}\text { Erdmann et al. } \\
2000 \text { (ITE) }\end{array}$ & IMS-6f @ ITE & $\begin{array}{l}\text { Produce SIMS actinide } \\
\text { particulate standards }\end{array}$ & $\begin{array}{l}\text { Nucleopore filters submerged in } \\
\text { ethanol and sonicated to release } \\
\text { particles. Suspension then pipetted } \\
\text { onto high purity carbon planchettes. }\end{array}$ & $\begin{array}{l}\text { SIMS U-isotope } \\
\text { composition was faithful } \\
\text { to standard value. }\end{array}$ & \begin{tabular}{|l|}
$1-2 \mathrm{nA} \mathrm{O}_{2}^{+}$ \\
few micron lateral \\
res.
\end{tabular} & ${ }^{234} \mathrm{U}{ }^{23}{ }^{135} \mathrm{U},{ }^{236} \mathrm{U},{ }^{238} \mathrm{U}$, \\
\hline
\end{tabular}




\begin{tabular}{|c|c|c|c|c|c|c|}
\hline $\begin{array}{l}\text { Authors and } \\
\text { affiliation }{ }^{1,2}\end{array}$ & Instrument and lab & Aim of study & SIMS particle mounting technique & Outcome & $\begin{array}{c}\text { Primary beam } \\
\text { information }\end{array}$ & $\begin{array}{c}\text { SIMS masses } \\
\text { analyzed }\end{array}$ \\
\hline $\begin{array}{l}\text { Esaka et al. } \\
2008 \\
\text { (JAERI) }\end{array}$ & $\begin{array}{l}\text { IMS-6f @ Unspec. } \\
\text { Loc. }\end{array}$ & $\begin{array}{l}\text { Determine effect of } \\
\text { particle size on SIMS U } \\
\text { isotope measurement }\end{array}$ & $\begin{array}{l}\text { Particles mounted on glassy carbon } \\
\text { stub, then transferred using gold } \\
\text { needle onto new carbon stub for } \\
\text { SIMS analysis based on size. }\end{array}$ & $\begin{array}{l}\text { Relationship between } \\
\text { particle size and analytical } \\
\text { precision was established. }\end{array}$ & $\begin{array}{l}1-2 \mathrm{nA} \mathrm{O}_{2}^{+} \\
<10 \mu \mathrm{m} \text { lateral } \\
\text { res. }\end{array}$ & $\begin{array}{l}{ }^{234} \mathrm{U},{ }^{235} \mathrm{U},{ }^{236} \mathrm{U},{ }^{238} \mathrm{U}, \\
\text { and }{ }^{238} \mathrm{U}^{1} \mathrm{H}\end{array}$ \\
\hline $\begin{array}{l}\text { Esaka et al. } \\
2011 \\
\text { (JAERI) }\end{array}$ & $\begin{array}{l}\text { IMS-6f @ Unspec. } \\
\text { Loc. }\end{array}$ & $\begin{array}{l}\text { Compare ICP-MS and } \\
\text { SIMS analysis for mixed } \\
\text { U-Pu oxides }\end{array}$ & $\begin{array}{l}\text { Mixed particles suspended in n- } \\
\text { dodecane and pippeted onto } \mathrm{Si} \\
\text { wafer. Particles of interest then } \\
\text { transferred onto glassy carbon } \\
\text { planchette via SEM viewing. }\end{array}$ & $\begin{array}{l}\text { Removal of certain } \\
\text { isobaric interferences } \\
\text { unrelated to mounting } \\
\text { technique will require } \\
\text { further investigation. }\end{array}$ & $4-15 \mathrm{nA} \mathrm{O}_{2}^{+}$ & $\begin{array}{l}{ }^{234} \mathrm{U},{ }^{235} \mathrm{U},{ }^{236} \mathrm{U},{ }^{238} \mathrm{U}, \\
{ }^{239} \mathrm{Pu}\end{array}$ \\
\hline $\begin{array}{l}\text { Esaka et al. } \\
2012 \\
\text { (JAERI) }\end{array}$ & $\begin{array}{l}\text { IMS-6f @ Unspec. } \\
\text { Loc. }\end{array}$ & $\begin{array}{l}\text { Use fission-track } \\
\text { detection to identify } \\
\text { particles of interest for } \\
\text { SIMS analysis }\end{array}$ & $\begin{array}{l}\text { Particles in polycarbonate solution } \\
\text { transferred and fixed onto glassy } \\
\text { carbon planchette followed by } \\
\text { analysis via SIMS. }\end{array}$ & $\begin{array}{l}\text { Polycarbonate film effects } \\
\text { U-isotope determination } \\
\text { by SIMS. Plasma ashing } \\
\text { overcomes this problem. }\end{array}$ & $\begin{array}{l}4-15 \mathrm{nA} \mathrm{O}_{2}^{+} \\
<10 \mu \mathrm{m} \text { lateral } \\
\text { res. }\end{array}$ & $\begin{array}{l}{ }^{234} \mathrm{U},{ }^{235} \mathrm{U},{ }^{236} \mathrm{U},{ }^{238} \mathrm{U}, \\
{ }^{238} \mathrm{U}^{1} \mathrm{H}\end{array}$ \\
\hline $\begin{array}{l}\text { Esaka et al. } \\
2007 \text { (JAERI) }\end{array}$ & $\begin{array}{l}\text { IMS-6f @ Unspec. } \\
\text { Loc. }\end{array}$ & $\begin{array}{l}\text { Test new method for } \\
\text { isolating particles of } \\
\text { interest before SIMS } \\
\text { analysis }\end{array}$ & $\begin{array}{l}\text { Particles transferred from collection } \\
\text { media onto glassy carbon planchettes } \\
\text { by vacuum impaction. No grease } \\
\text { coating applied. Particles of interest } \\
\text { identified by SEM transferred onto } \\
\text { separate planchette for SIMS } \\
\text { analysis. }\end{array}$ & $\begin{array}{l}\text { Technique allowed for } \\
\text { isolation of particles, thus } \\
\text { reducing contribution of } \\
\text { interfering species from } \\
\text { surrounding particles. }\end{array}$ & $\begin{array}{l}1-20 \mathrm{nA} \mathrm{O}_{2}^{+} \\
<10 \mu \mathrm{m} \text { lateral } \\
\text { res. }\end{array}$ & $\begin{array}{l}{ }^{234} \mathrm{U},{ }^{235} \mathrm{U},{ }^{236} \mathrm{U},{ }^{238} \mathrm{U}, \\
{ }^{238} \mathrm{U}^{1} \mathrm{H}\end{array}$ \\
\hline $\begin{array}{l}\text { Esaka et al. } \\
2009 \\
\text { (JAERI) }\end{array}$ & $\begin{array}{l}\text { IMS-6f @ Unspec. } \\
\text { Loc. }\end{array}$ & $\begin{array}{l}\text { Compare ICP-MS and } \\
\text { SIMS analysis for } \\
\text { safeguard applications }\end{array}$ & $\begin{array}{l}\text { Particles in swipe samples mounted } \\
\text { on glassy carbon stub by vacuum } \\
\text { impaction, then transferred using } \\
\text { gold needle onto new carbon stub for } \\
\text { SIMS analysis based on size }\end{array}$ & $\begin{array}{l}\text { For individual (isolated) } \\
\text { particle analysis, SIMS } \\
\text { and ICP-MS have similar } \\
\text { precision/accuracy. }\end{array}$ & $1-20 \mathrm{nA} \mathrm{O}_{2}^{+}$ & $\begin{array}{l}{ }^{234} \mathrm{U},{ }^{235} \mathrm{U},{ }^{236} \mathrm{U},{ }^{238} \mathrm{U}, \\
{ }^{238} \mathrm{U}^{1} \mathrm{H}\end{array}$ \\
\hline $\begin{array}{l}\text { Esaka \& } \\
\text { Magara } 2014 \\
(\text { JAERI) }\end{array}$ & $\begin{array}{l}\text { IMS-6f @ Unspec. } \\
\text { Loc. }\end{array}$ & $\begin{array}{l}\text { Use alpha-track detection } \\
\text { to identify particles of } \\
\text { interest for SIMS analysis }\end{array}$ & $\begin{array}{l}\text { Particles transferred onto silicon } \\
\text { wafers via micromanipulation } \\
\text { followed by coating with } \\
\text { polycarbonate solution and co- } \\
\text { location with alpha track recorder. } \\
\text { Coated particles of interest then } \\
\text { transferred onto glassy carbon } \\
\text { planchette followed by plasma } \\
\text { ashing before SIMS analysis. }\end{array}$ & $\begin{array}{l}\text { SIMS U-isotope } \\
\text { composition was faithful } \\
\text { to standard value. }\end{array}$ & $6-18 \mathrm{nA} \mathrm{O}_{2}^{+}$ & $\begin{array}{l}{ }^{234} \mathrm{U},{ }^{235} \mathrm{U},{ }^{236} \mathrm{U},{ }^{238} \mathrm{U}, \\
{ }^{238} \mathrm{U}^{1} \mathrm{H}\end{array}$ \\
\hline $\begin{array}{l}\text { Faure \& Dalger } \\
2017 \text { (CEA) }\end{array}$ & $\begin{array}{l}\text { IMS-7f @ Unspec. } \\
\text { Loc. }\end{array}$ & $\begin{array}{l}\text { Perform age-dating of U } \\
\text { particles }\end{array}$ & $\begin{array}{l}\text { Transfer of particles from swipe onto } \\
\text { carbon planchette coated with } \\
\text { polyisobutylene in nonane via } \\
\text { vacuum impaction. Before SIMS } \\
\text { analysis, planchette baked at } 400^{\circ} \mathrm{C} \\
\text { for } 30 \text { min. to eliminate organics. }\end{array}$ & $\begin{array}{l}\text { Age dating was } \\
\text { successfully carried out on } \\
\text { individual particles via } \\
\text { SIMS U isotope analysis. }\end{array}$ & $\begin{array}{l}150 \mathrm{nA} \mathrm{O}_{2}^{+} \text {for } \\
\text { location } \\
2-5 \mathrm{nA} \mathrm{O}_{2}^{+} \text {for } \\
\text { age } \\
150 \mathrm{nA} \text { for APM } \\
250 \mathrm{pA} \text { for } \mathrm{U} \\
\text { isotope }\end{array}$ & $\begin{array}{l}{ }^{230} \mathrm{Th},{ }^{234} \mathrm{U} \text { for age; } \\
{ }^{235} \mathrm{U},{ }^{238} \mathrm{U} \text { for } \mathrm{APM} ; \\
{ }^{235} \mathrm{U},{ }^{238} \mathrm{U} \text { for } \mathrm{U} \\
\text { isotope }\end{array}$ \\
\hline
\end{tabular}




\begin{tabular}{|c|c|c|c|c|c|c|}
\hline $\begin{array}{l}\text { Authors and } \\
\text { affiliation }{ }^{1,2}\end{array}$ & Instrument and lab & Aim of study & SIMS particle mounting technique & Outcome & $\begin{array}{c}\text { Primary beam } \\
\text { information }\end{array}$ & $\begin{array}{c}\text { SIMS masses } \\
\text { analyzed }\end{array}$ \\
\hline $\begin{array}{l}\text { Faure et al. } \\
2014 \text { (CEA) }\end{array}$ & $\begin{array}{l}\text { IMS-7f @ Unspec. } \\
\text { Loc. }\end{array}$ & $\begin{array}{l}\text { Determine F content of U } \\
\text { bearing particles by SIMS } \\
\text { and Investigate heat } \\
\text { treatment of mounts }\end{array}$ & $\begin{array}{l}\text { Transfer of particles from swipe onto } \\
\text { carbon planchette coated with } \\
\text { polyisobutylene in nonane via } \\
\text { vacuum impaction. Particles also } \\
\text { deposited in ethanol droplets onto } \\
\text { carbon planchettes. }\end{array}$ & $\begin{array}{l}\text { Heat treatment of particle } \\
\text { mounts (e.g., to remove } \\
\text { organics) induces F loss. } \\
\text { Organic fixing agent does } \\
\text { not appear to effect F } \\
\text { content or U isotope } \\
\text { values. }\end{array}$ & $\begin{array}{l}150 \mathrm{nA} \mathrm{O}_{2}^{+} \text {for } \\
\mathrm{APM} \\
250 \mathrm{pA} \mathrm{O}_{2}^{+} \text {for } \\
\text { measure. }\end{array}$ & $\begin{array}{l}{ }^{233} \mathrm{U},{ }^{234} \mathrm{U},{ }^{235} \mathrm{U},{ }^{238} \mathrm{U}, \\
{ }^{2}{ }^{238} \mathrm{UF} \text { for APM; } \\
{ }^{234} \mathrm{U},{ }^{235} \mathrm{U},{ }^{236} \mathrm{U},{ }^{238} \mathrm{U}, \\
{ }^{238} \mathrm{UH}{ }^{238} \mathrm{UF} \text { for } \\
\text { measure }\end{array}$ \\
\hline $\begin{array}{l}\text { Hedberg et al. } \\
2011 \text { (ITE) }\end{array}$ & $\begin{array}{l}\text { IMS-1280@UWA \& } \\
\text { IMS 4FE6-PC @ ITE }\end{array}$ & $\begin{array}{l}\text { Develop automated } \\
\text { particle recognition and } \\
\text { analysis } \\
\text { protocols/software }\end{array}$ & $\begin{array}{l}\text { Particulates from swipe samples } \\
\text { transferred onto pyrolitical graphite } \\
\text { planchettes via vacuum impaction } \\
\text { and particulates suspended in } \\
\text { isopropanol pipetted onto pyrolitical } \\
\text { graphic planchets. }\end{array}$ & \begin{tabular}{|l|} 
Automated Particle \\
Management software was \\
developed.
\end{tabular} & $\begin{array}{l}\text { Measure: } 1-5 \mathrm{nA} \\
\mathrm{O}_{2}^{+} \text {for } 4 \mathrm{FE} 6-\mathrm{PC} \\
\& 1280 \\
\text { APM: } 100- \\
200 \mathrm{nA} \text { on } 4 \mathrm{FE}- \\
6 \mathrm{PC} \text { and } 80- \\
130 \mathrm{nA} \text { on } 1280\end{array}$ & $\begin{array}{l}\text { 4FE6-PC: }{ }^{233} \mathrm{U},{ }^{234} \mathrm{U}, \\
{ }^{235} \mathrm{U},{ }^{238} \mathrm{U},{ }^{238} \mathrm{U}^{1} \mathrm{H} \\
1280:{ }^{234} \mathrm{U},{ }^{235} \mathrm{U} \\
{ }^{236} \mathrm{U},{ }^{238} \mathrm{U},{ }^{238} \mathrm{UH}\end{array}$ \\
\hline $\begin{array}{l}\text { Kips et al. } 2009 \\
\text { (EC \& UA) }\end{array}$ & $\begin{array}{l}\text { IMS-4f @ QuineticQ } \\
\text { (UK) }\end{array}$ & $\begin{array}{l}\text { Determine } \mathrm{F} \text { content of } \\
\mathrm{UO}_{2} \mathrm{~F}_{2} \text { particles }\end{array}$ & $\begin{array}{l}\text { Aerosol deposition chamber } \\
\text { produced particles collected directly } \\
\text { on graphite substrate. }\end{array}$ & $\begin{array}{l}\text { Difficulties related to } \\
\text { ionization efficiency } \\
\text { between } U \text { and } F \\
\text { complicate } F \\
\text { determination. } \\
\end{array}$ & $\begin{array}{l}2 \mathrm{nA} \mathrm{O}_{2}^{+} \\
10 \mu \mathrm{m} \text { beam } \\
\text { diameter }\end{array}$ & $\begin{array}{l}{ }^{238} \mathrm{U}^{19} \mathrm{~F},{ }^{238} \mathrm{U}^{16} \mathrm{O}^{19} \mathrm{~F} \\
{ }^{235} \mathrm{U}^{19} \mathrm{~F}_{2},{ }^{238} \mathrm{U}^{19} \mathrm{~F}_{2}\end{array}$ \\
\hline $\begin{array}{l}\text { Kips \& Kristo } \\
2009 \\
(\text { LLNL) }\end{array}$ & NanoSIMS@LLNL & $\begin{array}{l}\text { Determine impact of } \\
\text { environmental conditions } \\
\text { on } \mathrm{F} \text { content of } \mathrm{UO}_{2} \mathrm{~F}_{2} \\
\text { particles }\end{array}$ & $\begin{array}{l}\text { Aerosol deposition chamber } \\
\text { produced particles collected directly } \\
\text { on graphite substrate. }\end{array}$ & \begin{tabular}{|l|} 
Difficulties related to \\
ionization efficiency \\
between U \& F complicate \\
F determination.
\end{tabular} & $\begin{array}{l}\mathrm{O}^{-} ; 200-400 \mathrm{~nm} \\
\text { beam diameter } \\
\text { (unknown } \\
\text { intensity; prob a } \\
\text { few pA). } \\
\end{array}$ & $\begin{array}{l}{ }^{12} \mathrm{C},{ }^{16} \mathrm{O},{ }^{19} \mathrm{~F},{ }^{238} \mathrm{U} \\
{ }^{238} \mathrm{U}^{16} \mathrm{O},{ }^{238} \mathrm{U}^{19} \mathrm{~F} \\
{ }^{238} \mathrm{U}^{16} \mathrm{O}_{2},{ }^{238} \mathrm{U}^{19} \mathrm{~F}_{2}\end{array}$ \\
\hline $\begin{array}{l}\text { Kips et al. } 2007 \\
\text { (EC\&UA) }\end{array}$ & $\begin{array}{l}\text { ION-TOF SIMS @ } \\
\text { UA, IMS-4f \& 6f @ } \\
\text { ITE, IMS-4f @ } \\
\text { QineticQ (UK) }\end{array}$ & $\begin{array}{l}\text { Characterize U particles } \\
\text { produced by hydrolysis of } \\
\mathrm{UF}_{6}\end{array}$ & $\begin{array}{l}\text { Aerosol deposition chamber } \\
\text { produced particles collected directly } \\
\text { on graphite substrate. Before SIMS } \\
\text { analysis, particle mounts were heated } \\
\text { at } 350^{\circ} \mathrm{C} \text { for } 5 \mathrm{~h} \text {. }\end{array}$ & $\begin{array}{l}\text { Heat treatment of particle } \\
\text { mounts induces F loss. U } \\
\text { isotope composition can } \\
\text { be measured by SIMS. }\end{array}$ & $\begin{array}{l}1-2 \mathrm{nA} \mathrm{O}_{2}^{+} \text {with a } \\
\text { few micron } \\
\text { diameter@ ITU } \\
2 \mathrm{nA} \mathrm{O}_{2}^{+} @ \\
\text { QineticQ }\end{array}$ & $\begin{array}{l}\text { Variety of } \mathrm{U} \text { isotopes } \\
\text { and } \mathrm{F}\end{array}$ \\
\hline $\begin{array}{l}\text { Lehto et al. } \\
2003 \text { (VTT) }\end{array}$ & $\begin{array}{l}\text { VG IX70S@Unspec. } \\
\text { Loc. }\end{array}$ & $\begin{array}{l}\text { Develop method of } \\
\text { particle analysis on } \mathrm{Ga}^{+} \\
\text {source SIMS }\end{array}$ & $\begin{array}{l}\text { Particles extracted from swipes via } \\
\text { sonication in ethanol then transferred } \\
\text { onto carbon sheet discs as well as } \\
\text { planchettes. Some swipes also ashed, } \\
\text { followed by suspension of particles } \\
\text { into ethanol and transfer onto carbon } \\
\text { disc. }\end{array}$ & $\begin{array}{l}\text { Reasonably good } \\
\text { agreement with standard } \\
\text { compositions, but } \mathrm{O} \\
\text { flooding needed to } \\
\text { improve sensitivity for } \\
\text { small particles of interest. }\end{array}$ & $500 \mathrm{pA} \mathrm{Ga}^{+}$ & ${ }^{235} \mathrm{U}$ and ${ }^{238} \mathrm{U}$ \\
\hline $\begin{array}{l}\text { Pajo et al. } 2001 \\
\text { (UH) }\end{array}$ & $\begin{array}{l}\text { IMS-6f @ Unspec. } \\
\text { Loc. }\end{array}$ & $\begin{array}{l}\text { Compare } \mathrm{O} \text { isotope } \\
\text { measurement techniques } \\
\text { on } \mathrm{UO}_{2} \text { particles }\end{array}$ & $\begin{array}{l}\text { U particles deposited on polished } \\
\text { graphite planchette. }\end{array}$ & $\begin{array}{l}\text { Under Cs bombardment, } \\
\text { substantial background } \\
\text { from planchette can be } \\
\text { produced. }\end{array}$ & $5-10 \mathrm{nA}^{133} \mathrm{Cs}^{+}$ & ${ }^{18} \mathrm{O}^{-}$and ${ }^{16} \mathrm{O}^{-}$ \\
\hline
\end{tabular}




\begin{tabular}{|c|c|c|c|c|c|c|}
\hline $\begin{array}{l}\text { Authors and } \\
\text { affiliation } 1,2\end{array}$ & Instrument and lab & Aim of study & SIMS particle mounting technique & Outcome & $\begin{array}{c}\text { Primary beam } \\
\text { information }\end{array}$ & $\begin{array}{c}\text { SIMS masses } \\
\text { analyzed }\end{array}$ \\
\hline $\begin{array}{l}\text { Park et al. } 2017 \\
\text { (NCRD) }\end{array}$ & $\begin{array}{l}\text { SurfaceSeer-I \& IMS- } \\
\text { 7f Auto @ Unspec. } \\
\text { Loc. }\end{array}$ & $\begin{array}{l}\text { Compare TOF and } \\
\text { Dynamic SIMS } \\
\text { measurement techniques } \\
\text { for U particle } \\
\text { characterization }\end{array}$ & $\begin{array}{l}\text { Powdered material collected on } \\
\text { cotton swipes transferred to grease } \\
\text { (Apiezon L) coated carbon } \\
\text { planchette by vacuum impaction. }\end{array}$ & $\begin{array}{l}\text { Hydrocarbon peaks from } \\
\text { grease coating can be } \\
\text { eliminated by appropriate } \\
\text { pre-sputtering regime. }\end{array}$ & $1 \mathrm{nA} \mathrm{O}_{2}^{+}$ & $\begin{array}{l}\text { APM: }{ }^{235} \mathrm{U},{ }^{238} \mathrm{U}, \\
{ }^{235} \mathrm{UO}_{2},{ }^{238} \mathrm{UO}_{2} \\
\text { Measure: }{ }^{234} \mathrm{U},{ }^{235} \mathrm{U}, \\
{ }^{236} \mathrm{U}^{238}{ }^{23},{ }^{238} \mathrm{UH}, \\
{ }^{234} \mathrm{UO}_{2},{ }^{235} \mathrm{UO}_{2}, \\
{ }^{236} \mathrm{UO}_{2},{ }^{238} \mathrm{UO}_{2}, \\
{ }^{238} \mathrm{UO}_{2} \mathrm{H}\end{array}$ \\
\hline $\begin{array}{l}\text { Peres et al. } \\
2012 \text { (CFr) }\end{array}$ & IMS-1280@CFr & $\begin{array}{l}\text { Develop automated } \\
\text { particle management } \\
\text { using LG-SIMS }\end{array}$ & $\begin{array}{l}\text { U particulates suspended in nonane } \\
\text { and transferred onto pyrolitic carbon } \\
\text { planchettes before heat treatment. }\end{array}$ & $\begin{array}{l}\text { APM software for LG- } \\
\text { SIMS was developed to } \\
\text { handle U particulate } \\
\text { mounts. }\end{array}$ & $\begin{array}{l}\text { APM: } 500 \mathrm{nA} \mathrm{O}_{2}^{+} \\
\text {Measure: } 100 \mathrm{pA} \\
\text { to } 1 \mathrm{nA} \mathrm{O}_{2}^{+}\end{array}$ & $\begin{array}{l}{ }^{234} \mathrm{U},{ }^{235} \mathrm{U},{ }^{236} \mathrm{U},{ }^{238} \mathrm{U}, \\
\text { and }{ }^{238} \mathrm{U}^{1} \mathrm{H}\end{array}$ \\
\hline $\begin{array}{l}\text { Ranebo et al. } \\
2010 \text { (ITE) }\end{array}$ & $\begin{array}{l}\text { IMS-6f @ Unspec. } \\
\text { Loc. }\end{array}$ & $\begin{array}{l}\text { Produce mixed U-Pu } \\
\text { particle standards }\end{array}$ & $\begin{array}{l}\text { Uranium particles suspended in } \\
\text { propan-2-ol pipetted onto graphite } \\
\text { planchettes followed by thermal } \\
\text { evaporation and Pu particles } \\
\text { transferred onto carbon tape attached } \\
\text { to SIMS mounts by vacuum } \\
\text { impaction. } \\
\end{array}$ & $\begin{array}{l}\text { Standards were } \\
\text { successfully produced and } \\
\text { quantitatively analyzed } \\
\text { using SIMS. }\end{array}$ & $1-10 \mathrm{nA} \mathrm{O}_{2}^{+}$ & ${ }^{238} \mathrm{U},{ }^{242} \mathrm{Pu},{ }^{242} \mathrm{Pu}(?)$ \\
\hline $\begin{array}{l}\text { Sabioni et al. } \\
1998 \text { (UFOP) }\end{array}$ & IMS-4f@ LPS & $\begin{array}{l}\text { Study U self-diffusion in } \\
\mathrm{UO}_{2} \text { single crystals }\end{array}$ & $\begin{array}{l}\text { SIMS analysis of single } \mathrm{UO}_{2} \\
\text { crystals; mounting method not } \\
\text { discussed. }\end{array}$ & $\begin{array}{l}\text { Uranium diffusion } \\
\text { coefficients were } \\
\text { determined by SIMS } \\
\text { measurement. } \\
\end{array}$ & $\mathrm{O}^{+}$ & ${ }^{235} \mathrm{U},{ }^{234} \mathrm{U},{ }^{238} \mathrm{U}$ \\
\hline $\begin{array}{l}\text { Sharp et al. } \\
2016 \text { (NIST) }\end{array}$ & $\begin{array}{l}\text { IMS-1270 E7 @ } \\
\text { Unspec. Loc. }\end{array}$ & $\begin{array}{l}\text { Characterize secondary } \\
\text { ion yield from U particles } \\
\text { and relationship to } \\
\text { substrate type }\end{array}$ & $\begin{array}{l}\text { U particles suspended in isopropanol } \\
\text { deposited onto pyrolytic graphite } \\
\text { planchette followed by gold coating. } \\
\text { Samples also prepared on p-type } \\
\text { silicon substrate. }\end{array}$ & $\begin{array}{l}\text { Determined that graphite } \\
\text { produces better yield } \\
\text { under } \mathrm{O}^{-} \text {and } \mathrm{O}_{2}^{-} \text {but } \\
\text { silicon is better under } \mathrm{O}_{2}^{+} \text {. }\end{array}$ & $\begin{array}{l}\mathrm{O}^{-}, \mathrm{O}_{2}^{-}, \mathrm{O}_{2}^{+}(1 \text { to } \\
1-15 \mathrm{nA})\end{array}$ & ${ }^{238} \mathrm{U}$ \\
\hline $\begin{array}{l}\text { Simons \& } \\
\text { Fassett } 2017 \\
\text { (NIST) }\end{array}$ & $\begin{array}{l}\text { IMS-1270 E7 @ } \\
\text { Unspec. Loc. }\end{array}$ & $\begin{array}{l}\text { Modeling of experimental } \\
\text { results to determine } \\
\text { hydride interference }\end{array}$ & $\begin{array}{l}\text { U and Pu standards mounted on } \\
\text { pyrolytic graphite planchettes, } \\
\text { vitreous carbon planchettes, and } \\
\text { silicon substrates. }\end{array}$ & $\begin{array}{l}\text { Pyrolitic graphite and } \\
\text { vitreous carbon can } \\
\text { contain up to } 1 \% \\
\text { hydrogen, thus posing an } \\
\text { interference on }{ }^{236} \mathrm{U} \\
\text { measurement. Silicon } \\
\text { substrate is equally } \\
\text { complex. }\end{array}$ & $0.75-5 \mathrm{nA} \mathrm{O}^{-}$ & $\begin{array}{l}{ }^{234} \mathrm{U}^{235} \mathrm{U},{ }^{236} \mathrm{U}, \\
{ }^{235} \mathrm{U}^{1} \mathrm{H},{ }^{238} \mathrm{U},{ }^{238} \mathrm{U}^{1} \mathrm{H}\end{array}$ \\
\hline $\begin{array}{l}\text { Tamborini et al. } \\
1998 \text { (ITE) }\end{array}$ & $\begin{array}{l}\text { IMS-6f@ Courbevoie } \\
\text { (Fr) }\end{array}$ & $\begin{array}{l}\text { Develop SIMS method } \\
\text { for nuclear particles }\end{array}$ & $\begin{array}{l}\text { Particles from swipes transferred to } \\
\text { Leit-Tabs (adhesive support) then } \\
\text { coated with Carbon before loading } \\
\text { into SIMS. }\end{array}$ & $\begin{array}{l}\text { Substrate produced a } \\
\text { background signal that } \\
\text { was at times significant. }\end{array}$ & $100-200 \mathrm{nA} \mathrm{O}_{2}^{+}$ & $\begin{array}{l}{ }^{234} \mathrm{U},{ }^{235} \mathrm{U},{ }^{236} \mathrm{U},{ }^{238} \mathrm{U}, \\
{ }^{238} \mathrm{U}^{1} \mathrm{H}\end{array}$ \\
\hline
\end{tabular}




\begin{tabular}{|c|c|c|c|c|c|c|}
\hline $\begin{array}{l}\text { Authors and } \\
\text { affiliation } 1,2\end{array}$ & Instrument and lab & Aim of study & SIMS particle mounting technique & Outcome & $\begin{array}{c}\text { Primary beam } \\
\text { information }\end{array}$ & $\begin{array}{c}\text { SIMS masses } \\
\text { analyzed }\end{array}$ \\
\hline $\begin{array}{l}\text { Tamborini et al. } \\
2002 \text { (ITE) }\end{array}$ & $\begin{array}{l}\text { IMS-6f @ ITE \& } \\
\text { IMS-3f at LLNL }\end{array}$ & $\begin{array}{l}\text { Develop O isotope } \\
\text { measurement of U } \\
\text { particles as a diagnostic } \\
\text { tool in nuclear forensics }\end{array}$ & $\begin{array}{l}\mathrm{U} \text { particles suspended in alcohol and } \\
\text { then pipetted onto conductive carbon } \\
\text { planchet. }\end{array}$ & $\begin{array}{l}\text { Oxygen blank contribution } \\
\text { from graphite is slightly } \\
\text { worst than gold, but } \\
\text { overall is negligible. }\end{array}$ & $\begin{array}{l}5-10 \mathrm{nA}^{133} \mathrm{Cs}^{+} @ \\
\text { ITE } \\
0.60 \mathrm{nA}{ }^{133} \mathrm{Cs}^{+} @ \\
\text { LLNL }\end{array}$ & ${ }^{18} \mathrm{O}^{-}$and ${ }^{16} \mathrm{O}^{-}$ \\
\hline $\begin{array}{l}\text { Tamborini et al. } \\
\text { 2002b (ITE) }\end{array}$ & IMS-6f@ITE & $\begin{array}{l}\text { Measure } \mathrm{U}, \mathrm{Pu}, \text { and } \mathrm{O} \\
\text { isotope composition on } \\
\text { nuclear particles }\end{array}$ & $\begin{array}{l}\text { Particles suspended in alcohol and } \\
\text { deposited onto polished carbon } \\
\text { planchette. Particles said to be } \\
\text { adhered to substrate as demonstrated } \\
\text { by lack of charging during } \\
\text { sputtering. }\end{array}$ & $\begin{array}{l}\text { No effect of substrate on } \\
\text { isotope measurements. }\end{array}$ & $\begin{array}{l}\text { Age dating: } 1- \\
2 \mathrm{nA} \mathrm{O}_{2}^{+} \\
\mathrm{O}^{+} \text {isotope: } \\
5-10 \mathrm{nA}^{133} \mathrm{Cs}^{+}\end{array}$ & $\begin{array}{l}{ }^{234} \mathrm{U},{ }^{235} \mathrm{U},{ }^{236} \mathrm{U}, \\
{ }^{238} \mathrm{Pu},{ }^{239} \mathrm{Pu},{ }^{16} \mathrm{O},{ }^{18} \mathrm{O}\end{array}$ \\
\hline $\begin{array}{l}\text { Tarolli et al. } \\
2016 \\
(\mathrm{PNNL})\end{array}$ & $\begin{array}{l}\text { IMS-1280-HR @ } \\
\text { Unspec. Loc. }\end{array}$ & $\begin{array}{l}\text { Fuse SIMS \& EDS to } \\
\text { develop high resolution } \\
\text { isotope analysis of } \\
\text { nuclear particles with } \\
\text { high throughput workflow }\end{array}$ & $\begin{array}{l}\text { Particles suspended in non-polar } \\
\text { solvent via ultrasonication followed } \\
\text { dispersion onto laser scribed vitreous } \\
\text { carbon planchette by pipetting } 5- \\
10 \mu \mathrm{L} \text {. Particles of interest were } \\
\text { moved using needles and mounted } \\
\text { on new planchettes. }\end{array}$ & $\begin{array}{l}\text { Workflow development } \\
\text { was successful; mounting } \\
\text { technique allowed } \\
\text { particles to be moved from } \\
\text { one planchette to another } \\
\text { as needed. }\end{array}$ & $10 \mathrm{nA} \mathrm{O}^{-}$ & $\begin{array}{l}{ }^{234} \mathrm{U}+,{ }^{235} \mathrm{U}+,{ }^{236} \mathrm{U}, \\
{ }^{238} \mathrm{U},{ }^{238} \mathrm{U}^{1} \mathrm{H}+\end{array}$ \\
\hline $\begin{array}{l}\text { Wellons et al. } \\
2017 \text { (NSD- } \\
\text { SRNL) }\end{array}$ & $\begin{array}{l}\text { IMS-1280 LG @ } \\
\text { Unspec. Loc. }\end{array}$ & $\begin{array}{l}\text { Apply U particulate test } \\
\text { samples to automated } \\
\text { particle management } \\
\text { protocol validation }\end{array}$ & $\begin{array}{l}\text { Test particles created by aerosol } \\
\text { generators deposited onto 'carbon } \\
\text { stubs.' }\end{array}$ & $\begin{array}{l}\text { Particles are easily } \\
\text { resolvable from } \\
\text { background (e.g., stub } \\
\text { material) by APM } \\
\text { protocols. }\end{array}$ & Not reported & Not reported \\
\hline $\begin{array}{l}\text { Willingham } \\
\text { et al. } 2016 \\
\text { (PNNL) }\end{array}$ & $\begin{array}{l}\text { Modified IMS 4-f @ } \\
\text { PNNL }\end{array}$ & $\begin{array}{l}\text { Refine method for } \\
\text { automated U particle } \\
\text { analysis by SIMS }\end{array}$ & $\begin{array}{l}\text { Study mentions use of conductive } \\
\text { swipes by others (no refs). Particles } \\
\text { in this study were suspended in } \\
\text { nonpolar solvent (Vetrel XF), } \\
\text { dispersed on vitrified carbon } \\
\text { planchettes, and then introduced into } \\
\text { the SIMS following drying. }\end{array}$ & $\begin{array}{l}\text { Automated protocols for } \\
\text { particle identification and } \\
\text { analysis were developed. } \\
\text { Study noted that the } \\
\text { suspension dispersion } \\
\text { method was not as } \\
\text { common as vacuum } \\
\text { impaction but was used by } \\
\text { the IAEA to analyze } \\
\text { particles from swipes. }\end{array}$ & $100 \mathrm{nA} \mathrm{O}^{-}$ & $\begin{array}{l}{ }^{234} \mathrm{U},{ }^{235} \mathrm{U},{ }^{236} \mathrm{U},{ }^{238} \mathrm{U}, \\
{ }^{238} \mathrm{U}^{1} \mathrm{H}\end{array}$ \\
\hline $\begin{array}{l}\text { Wallenius et al. } \\
2001 \text { (ITE) }\end{array}$ & IMS-6f@ITE & $\begin{array}{l}\text { Develop method of age } \\
\text { determination of particles } \\
\text { by SIMS }\end{array}$ & $\begin{array}{l}\text { Particles on tweezers washed onto } \\
\text { polished carbon planchettes with } \\
\text { ethanol then coated in carbon. }\end{array}$ & $\begin{array}{l}\text { Age dating by SIMS was } \\
\text { successful. }\end{array}$ & $\begin{array}{l}1 \text { to } 2 \mathrm{nA} \mathrm{O}_{2}^{+} \text {with } \\
\text { diameter of a few } \\
\text { microns }\end{array}$ & $\begin{array}{l}{ }^{234} \mathrm{U},{ }^{235} \mathrm{U},{ }^{236} \mathrm{U}, \\
{ }^{238} \mathrm{Pu},{ }^{239} \mathrm{Pu},{ }^{240} \mathrm{Pu}\end{array}$ \\
\hline \multicolumn{7}{|c|}{ Unknown particles in weapons material matrix } \\
\hline $\begin{array}{l}\text { Ranebo et al. } \\
2007 \text { (ITE) }\end{array}$ & $\begin{array}{l}\text { IMS-6f @ Unspec. } \\
\text { Loc. }\end{array}$ & $\begin{array}{l}\text { Characterize individual } U \\
\text { particles in weapons } \\
\text { matrix }\end{array}$ & $\begin{array}{l}\text { Particles separated from matrix are } \\
\text { mounted on adhesive carbon tape } \\
\text { and then further manipulated in } \\
\text { attempt to isolate them from matrix } \\
\text { and contaminants. }\end{array}$ & \begin{tabular}{|l|} 
Complex matrix coupled \\
with sample mounting \\
issues led to uncertainty in \\
isotope measurement.
\end{tabular} & $\begin{array}{l}1 \text { to } 20 \mathrm{nA} \mathrm{O}_{2}^{+} \\
\text {Spot size approx. } \\
1 \mu \mathrm{m}\end{array}$ & $\begin{array}{l}{ }^{235} \mathrm{U},{ }^{238} \mathrm{U},{ }^{239} \mathrm{Pu}, \\
{ }^{240} \mathrm{Pu}\end{array}$ \\
\hline
\end{tabular}




\begin{tabular}{|c|c|c|c|c|c|c|}
\hline $\begin{array}{l}\text { Authors and } \\
\text { affiliation } 1,2\end{array}$ & Instrument and lab & Aim of study & SIMS particle mounting technique & Outcome & $\begin{array}{c}\text { Primary beam } \\
\text { information }\end{array}$ & $\begin{array}{c}\text { SIMS masses } \\
\text { analyzed }\end{array}$ \\
\hline \multicolumn{7}{|l|}{ Review papers } \\
\hline $\begin{array}{l}\text { Tamborini } 2004 \\
\text { (ITE) }\end{array}$ & $\begin{array}{l}\text { IMS-6f @ Unspec. } \\
\text { Loc. }\end{array}$ & $\begin{array}{l}\text { Summarize methods used } \\
\text { at ITE for nuclear particle } \\
\text { analysis }\end{array}$ & $\begin{array}{l}\text { Particles are deposited on a polished } \\
\text { graphite planchette. }\end{array}$ & $\begin{array}{l}\text { No new data presented; } \\
\text { only a review. }\end{array}$ & - & - \\
\hline $\begin{array}{l}\text { Walter } 2011 \\
\text { (KIT-INE) }\end{array}$ & $\mathrm{N} / \mathrm{A}$ & $\begin{array}{l}\text { Summarize use of SIMS } \\
\text { and other techniques for } \\
\text { nuclear particle analysis } \\
\text { including review of } \\
\text { particle production } \\
\text { techniques }\end{array}$ & $\begin{array}{l}\text { Several methods mentioned } \\
\text { including embedding of Pu particles } \\
\text { in } \mathrm{Si} / \mathrm{O} \text {-rich matrix, mounting on } \\
\text { silicon wafers, suspension in heptane } \\
\text { followed by dispersion onto graphite. }\end{array}$ & $\begin{array}{l}\text { Author provided a } \\
\text { generalized summary of } \\
\text { particle analysis. Note that } \\
\text { there is a detailed section } \\
\text { in particle production } \\
\text { methods. }\end{array}$ & - & - \\
\hline
\end{tabular}

${ }^{1}$ References can be found in the reference section of the commissioning plan.

${ }^{2}$ CEA: Commission de l'Energie Atomique (Arpajon, France); CFr : Cameca France (Paris, France); EC: European Commission, General Directorate Joint Research Centre, Institute for Reference Materials and Measurements (Geel, Belgium); IAEA: International Atomic Energy Agency (Vienna, Austria); ITE: Institute for Transuranium Elements (Karlsruhe, Germany); JAERI: Japan Atomic Energy Research Institute (Ibaraki, Japan); KFKI: KFKI Atomic Energy Research Institute (Budapest, Hungary); KIT-INE:

Karlsruhe Institute of Technology, Institute for Nuclear Waste Disposal (Karlsruhe, Germany); LLNL: Lawrence Livermore National Laboratory (California, USA); LPS: Laboratoire de Physique des Solides/CNRS (Meudon/Bellevue, France); NCRD: Nuclear Chemistry Research Division (Atomic Energy Research Institute: Daejeon, Korea); NIST: National Institute of Standards and Technology (Maryland, USA); NSD-SRNL: National Security Directorate, Savanah River National Laboratory (Georgia, USA); PNNL: Pacific Northwest National Laboratory (Washington, USA); UA: University of Antwerp (Antwerpen, Belgium); UFOP: Universidade Federal de Ouro Preto, Departamento de 
